\title{
Developmental programming: Sex-specific programming of growth upon prenatal bisphenol A exposure
}

\author{
Arpita Kalla Vyas ${ }^{1}$ (D) | Almudena Veiga-Lopez ${ }^{2}$ | Wen $\mathrm{Ye}^{3}$ | Bachir Abi Salloum ${ }^{4}$ | \\ David H. Abbott ${ }^{5}$ | Shengping Yang ${ }^{6}$ | Chunyang Liao ${ }^{7}$ | Kurunthachalam Kannan ${ }^{7}$ | \\ Vasantha Padmanabhan ${ }^{4}$
}

${ }^{1}$ College of Medicine, California Northstate University, Elk Grove, California

${ }^{2}$ Department of Animal Science, Michigan State University, East Lansing, Michigan

${ }^{3}$ Biostatistics Department, School of Public Health, Ann Arbor, Michigan

${ }^{4}$ Department of Pediatrics, University of Michigan, Ann Arbor, Michigan

${ }^{5}$ Department of Obstetrics and Gynecology and Wisconsin National Primate Research Center, University of Wisconsin, Madison, Wisconsin

${ }^{6}$ Department of Biostatistics, Pennington Biomedical Research Center, Baton Rouge, Louisiana

${ }^{7}$ New York State Department of Health, Wadsworth Center, Albany, New York

\section{Correspondence}

Arpita Vyas, College of Medicine, California North State University, 9700 West Taron Drive, Elk Grove, CA 95757, USA.

Email: arpita.vyas@cnsu.edu

Vasantha Padmanabhan, Department of Pediatrics, University of Michigan, 7510 MSRB I, 1150 West Medical Center Drive, Ann Arbor, MI 48109, USA.

Email: vasantha@umich.edu

\begin{abstract}
In both human and animals, in utero exposure to bisphenol A (BPA), an endocrinedisrupting chemical used in the production of plastics and epoxy resins, has been shown to affect offspring reproductive and metabolic health during adult life. We hypothesized that the effect of prenatal exposure to environmentally relevant doses of BPA will be evident during fetal organogenesis and fetal/postnatal growth trajectory. Pregnant ewes were administered BPA subcutaneously from 30 to 90 days of gestation (term 147 days). Fetal organ weight, anthropometric measures, maternal/fetal hormones and postnatal growth trajectory were measured in both sexes. Gestational BPA administration resulted in higher accumulation in male than female fetuses only at fetal day 65 , with minimal impact on fetal/maternal steroid milieu in both sexes at both time points. BPA-treated male fetuses were heavier than BPA-treated female fetuses at fetal day 90 whereas this sex difference was not evident in the control group. At the organ level, liver weight was reduced in prenatal BPA-treated female fetuses, while heart and thyroid gland weights were increased in BPA-treated male fetuses relative to their sex-matched control groups. Prenatal BPA treatment also altered the postnatal growth trajectory in a sex-specific manner. Males grew slower during the early postnatal period and caught up later. Females, in contrast, demonstrated the opposite growth trend. Prenatal BPA-induced changes in fetal organ differentiation and early life growth strongly implicate translational relevance of in utero contributions to reproductive and metabolic defects previously reported in adult female offspring.
\end{abstract}

\section{KEYWORDS}

developmental origins of health and disease, endocrine disruptors, obesity, obesogens

\section{1 | INTRODUCTION}

Intrauterine growth restriction (IUGR) is defined as birth weight and/or length below the 10th percentile for gestational age secondary to pathological restriction of fetal growth in utero (KanakaGantenbein, Mastorakos, \& Chrousos, 2003; Romo, Carceller, \&
Tobajas, 2009). Incidence of IUGR in newborns of term pregnancies ranges from 3\% to 7\% (Romo et al., 2009). IUGR followed by catchup growth has been associated with chronic disease later in life, including development of hypertension, impaired glucose tolerance, type 2 diabetes and lipid abnormalities (Barker, 2004; Valsamakis, Kanaka-Gantenbein, Malamitsi-Puchner, \& Mastorakos, 2006). 
Genetic factors account for one-third of human IUGR births, and twothirds are thought to be secondary to the adverse in utero environment (Valsamakis et al., 2006), including infection, disease states, nutritional deficit/excess, maternal stress, endocrine abnormalities, smoking or alcohol consumption, and exposure to environmental chemicals (Hakim, Padmanabhan, \& Vyas, 2017).

Programming of IUGR can be mediated by alteration of the fetomaternal hormonal milieu (Fowden, Giussani, \& Forhead, 2006). As steroid hormones orchestrate the dialogue between the uterine environment and the fetus, inappropriate exposure to sex steroids, native or environmental, can reprogram fetal development (Padmanabhan \& Veiga-Lopez, 2011). Additionally, alterations in the gestational hormonal milieu can affect postnatal growth of the IUGR fetus leading to catch-up growth and permanent defects throughout the lifespan of the individual. Such reprogramming of pre- and postnatal growth has been linked to cardiometabolic and reproductive dysfunction (Manikkam et al., 2004; Ong, Ahmed, Emmett, Preece, \& Dunger, 2000; Ong \& Dunger, 2002).

In recent years, endocrine-disrupting chemicals (EDCs) that mimic both estrogenic and androgenic actions have received considerable attention relative to pregnancy outcomes and origin of human disease (Veiga-Lopez et al., 2015; Veiga-Lopez, Pu, Gingrich, \& Padmanabhan, 2018; Vom Saal, Nagel, Coe, Angle, \& Taylor, 2012). One such ubiquitous EDC with estrogenic and anti-androgenic actions is bisphenol A (BPA), used in the manufacture of plastics and epoxy resins used in consumer products (vom Saal \& Hughes, 2005). Worldwide, >7 billion pounds of BPA are produced annually, generating 1 million dollars per day in revenue for corporations (Erler \& Novak, 2010). Human exposure to BPA occurs through dust, air and water (Vandenberg, Hunt, Myers, \& Vom Saal, 2013). Regulatory agencies, such as the Environmental Protection Agency, the Federal Drug Administration and the National Toxicology Program have set different threshold doses of BPA ( 50,5 and $0.5 \mathrm{mg} / \mathrm{kg} /$ day, respectively (Beronius, Ruden, Hakansson, \& Hanberg, 2010; Erler \& Novak, 2010) below which adverse effects are not present. BPA has been found in maternal circulation, amniotic fluid, adipose tissue, liver, placenta and breast milk (Calafat et al., 2009; Ikezuki, Tsutsumi, Takai, Kamei, \& Taketani, 2002; Sun et al., 2004). However, there are only a handful of human prospective studies that have assessed birth outcomes following prenatal BPA exposure (Snijder et al., 2013). Our recent study found that elevated first trimester BPA concentrations are associated with increased oxidative stress (Veiga-Lopez et al., 2015) leading to low birth weight in female, but not male offspring (Veiga-Lopez et al., 2015). The fact that higher maternal BPA concentrations at term were not associated with low birth weight (Padmanabhan et al., 2008; Veiga-Lopez et al., 2015) in these human studies emphasizes the importance of windows of susceptibility, particularly during pregnancy. Other epidemiological studies have found prenatal BPA exposure to be positively associated with offspring body mass index in early-to-mid-childhood (Vafeiadi et al., 2016; Yang et al., 2017), which is also a risk factor for the adult origins of disease.

Animal models have been used to address the effects of BPA on pregnancy and offspring outcomes to establish causality. Studies with precocial models, exhibiting developmental trajectories similar to humans, are essential for establishing causality of developmentally programmed pathologies that can be translated into novel human therapies. Sheep models, in particular, have been extensively used to assess pregnancy outcomes and developmental origin of diseases stemming from inappropriate exposure to native steroids and environmental steroid mimics (Padmanabhan, Sarma, Savabieasfahani, Steckler, \& Veiga-Lopez, 2010). Specifically, prenatal exposure to $5 \mathrm{mg} / \mathrm{kg} /$ day BPA from gestation day GD30 to GD90 (term: 147 days), resulting in maternal BPA concentrations twofold higher than the highest values observed in pregnant US women (Padmanabhan et al., 2008; Savabieasfahani, Kannan, Astapova, Evans, \& Padmanabhan, 2006), deliver low birth weight female offspring exhibiting reproductive cycle and metabolic dysfunction, including insulin resistance, adipocyte hypertrophy, and elevated proinflammatory markers in adipose tissue (Abi Salloum, Steckler, Herkimer, Lee, \& Padmanabhan, 2013; Savabieasfahani et al., 2006; Veiga-Lopez, Beckett, Abi Salloum, Ye, \& Padmanabhan, 2014).

Considering the non-monotonic dose-responses that have been observed relative to the impact of BPA (Vandenberg et al., 2014), as well as the limited number of reports addressing the early impact of BPA in precocial animals, the primary objectives of the present study were to (1) determine BPA concentrations achieved in both mother and fetus following gestational exposure to BPA at doses spanning human exposure levels, and (2) assess the effects of prenatal BPA exposure on birth and organ weights, and postnatal growth trajectory, key biomarkers for assessing the risk of adult-onset disease. As steroid hormones are major regulators of the growth trajectory, and BPA alters steroidogenesis (Bloom, Mok-Lin, \& Fujimoto, 2016; Peretz et al., 2014), our third objective was to determine the effects of prenatal BPA exposure on maternal/fetal steroid hormone milieu and its association with fetal organ weights.

\section{2 | MATERIALS AND METHODS}

The study was conducted at the University of Michigan Sheep Research Facility (Ann Arbor, Ml; $42^{\circ} 18^{\prime} \mathrm{N}$ ). All procedures were approved by the Institutional Animal Care and Use Committee of the University of Michigan and are consistent with the National Institutes of Health Guide for Use and Care of Animals. Healthy adult Suffolk sheep between the ages of 3 and 5 years were purchased from local farmers and used for generating control and prenatal BPA-treated animals. Animals were blocked by maternal weight and body score and distributed between control and BPA-treated groups. Details regarding animal maintenance, breeding and lambing have been described previously (Veiga-Lopez et al., 2016). Briefly, ewes were group-fed daily with $0.5 \mathrm{~kg}$ shelled corn and 1.0-1.5 kg alfalfa hay/ewe and mated to raddled Suffolk rams. Pregnant ewes maintained good health throughout the pregnancy. They were weighed weekly and the mean weight gains during pregnancies were determined. After weaning at $\sim 8$ weeks of age, lambs were maintained outdoors and fed a pelleted 
diet (Shur-Gain; Nutreco Canada Inc.) comprised of $3.6 \mathrm{MCal} / \mathrm{kg}$ digestible energy and $18 \%$ crude protein.

Two studies were conducted. Study 1 addressed the long-term consequences of prenatal BPA treatment and therefore offspring were maintained from birth to adulthood. Study 2 focused on determining maternal and fetal milieu and fetal organ weights. For this study, only the mid dose $(0.5 \mathrm{mg} / \mathrm{kg} /$ day $)$ was selected, as this was more environmentally relevant.

\section{1 | Study 1: Effects of prenatal bisphenol A on birth weight and postnatal growth trajectory}

Gestational BPA treatment consisted of daily subcutaneous (s.c.) BPA injections into dams of 0.05 (low), 0.5 (medium) or 5 (high) mg/kg/day of BPA (purity $\geq 99 \%$, cat. no. 239658; Sigma-Aldrich Chemical Co.) in corn oil from GD30 to GD90 (term: 147 days). Control dams received corn oil injections, alone. Umbilical arterial BPA concentrations using the medium dose are already published (Veiga-Lopez, Luense, Christenson, \& Padmanabhan, 2013) and approximate maternal BPA blood levels have been reported for US women (Padmanabhan et al., 2008). Offspring were delivered by 14, 21, 26 and 22 dams, respectively, in control, low, medium and high BPA treatment groups. Final experimental group sizes for control, low, medium and high BPA treatments were $8,12,13$ and 7 , respectively for female offspring, and 6, 9, 13 and 15 for male offspring.

Newborn samples were collected by jugular venipuncture in sodium fluoride/potassium oxalate tubes (BD Vacutainer) and plasma frozen at $-20^{\circ} \mathrm{C}$ until assayed for glucose and insulin. From day of birth to 11 weeks of age, females and male offspring were weighed weekly, after which males were not maintained to avoid unwanted pregnancies in the flock. After 11 weeks, female weights were taken weekly until $\sim 6$ months of age, and monthly thereafter until they were $\sim 20$ months old.

\subsection{Study 2: Effect of prenatal bisphenol A on maternal and fetal steroid, hormones and organ weights}

To determine the early effects of gestational BPA treatment, dams received daily s.c. injections of either the medium BPA dose (0.5 mg/kg/day) or corn oil (controls). This medium BPA dose achieved circulating levels of free BPA of $\sim 2.6 \mathrm{ng} / \mathrm{mL}$ in the umbilical artery of female fetus, approximating median values found in the urine of pregnant women and cord blood in human studies (Veiga-Lopez et al., 2013). Dams from the control and BPA groups were anesthetized on GD65 or GD90 with ketamine hydrochloride (Fort Dodge Animal Health; 3-4 mg/kg, i.v.) and xylazine (Anased Injection; 0.4 mg/kg/ewe, i.m.), and subsequently maintained under general anesthesia with isoflurane (RxElite Holdings Inc.). Umbilical arterial and venous samples were collected after accessing the gravid uterus via the midline and uterine wall incisions, as previously described (Veiga-Lopez et al., 2011). Samples were frozen until assayed for free and total BPA, androstenedione, cortisol, dehydroepiandrosterone (DHEA), deoxycorticosterone (DOC), 11-deoxycortisol, estradiol, estrone, glucose, insulin, pregnenolone, 17-hydroxypregnenolone, 17hydroxyprogesterone and testosterone.

Fetuses were then removed and killed by intracardiac barbiturate administration. Fetal body measures were undertaken and tissues procured. After removal of fetuses, mothers were also killed with a barbiturate overdose (15 mL, i.v. Fatal Plus; Vortech Pharmaceuticals). Group sizes for GD65 comprised nine female and 11 male fetuses delivered by 10 dams for BPA, and nine female and six male fetuses delivered by eight dams for controls. The GD90 groups comprised nine female and four male fetuses delivered from seven dams for BPA, and eight female and 10 male fetuses delivered from nine dams for controls. Fetal measurements included anogenital distance (AGD), crown to rump length (from the highest midpoint on the top of the head to the base of the tail), head circumference, fetal weight, as well as the weights of adrenal, brain, heart, kidney liver, lung, ovaries, testes, pancreas, pituitary, spleen, thymus, thyroid and uterus. The ratios of organ weights to body weight were determined.

\section{3 | Hormonal and metabolic measures}

Plasma concentrations of androstenedione, cortisol, DHEA, DOC, 11-deoxycortisol, estradiol, estrone, pregnenolone, 17hydroxypregnenolone, 17-hydroxyprogesterone and testosterone were assayed in a subset of maternal and umbilical cord samples collected at GD65 and GD90. The steroid hormone determinations were undertaken at the Optimized Analytical Solutions Laboratories, LLC using high-performance liquid chromatography (HPLC)/tandem mass spectrometry (MS/MS) Agilent MassHunter Workstation Data Acquisition for Triple Quad B.03.01 (B2065) and Agilent MassHunter Quantitative Analysis for QQQ (B.04.00/Build 4.0.225.0) with electrospray ionization (ESI). Samples were subjected to a liquid/liquid extraction method followed by derivatization with dansyl chloride to enable the detection of estrone and estradiol. Calibration curves of steroid hormone standard/internal standard peak area ratio versus steroid concentration were constructed and a weighted $1 / \times 2$ linear regression applied to the data. Concentrations of steroid hormones in samples were defined based on the appropriate calibration curve. Commercially obtained female monkey plasma was used as quality controls (for cortisol, estradiol and testosterone: Sigma-Aldrich; and for androstenedione, DHEA, DOC, 11-deoxycortisol, estrone, pregnenolone, 17-hydroxypregnenolone, 17-hydroxyprogesterone: Steraloids Inc.). Lower detection limits were: androstenedione $0.1 \mathrm{ng} / \mathrm{mL}$, cortisol $0.5 \mathrm{ng} / \mathrm{mL}$, DHEA $0.5 \mathrm{ng} / \mathrm{mL}$, 11-deoxycortisol $0.05 \mathrm{ng} / \mathrm{mL}$, DOC $0.05 \mathrm{ng} / \mathrm{mL}$, estradiol $5 \mathrm{pg} / \mathrm{mL}$, estrone $5 \mathrm{pg} / \mathrm{mL}$, pregnenolone $1 \mathrm{ng} / \mathrm{mL}$, 17-hyrdoxypregnenolone $1 \mathrm{ng} / \mathrm{mL}$, 17-hydroxyprogesterone $0.2 \mathrm{ng} / \mathrm{mL}$ and testosterone $0.02 \mathrm{ng} / \mathrm{mL}$. The respective coefficients of variation were androstenedione $3 \%$, cortisol 11\%, DHEA $8 \%$, DOC $19 \%$, 11-deoxcortisol 5\%, estradiol $2 \%$, estrone $4 \%$, pregnenolone 16\%, 17-hyrdoxypregnenolone 16\%, 17-hydroxyprogesterone $2 \%$ and testosterone $8 \%$. 
Plasma insulin and glucose were measured in all maternal/umbilical cord blood samples collected at GD65 and GD90 (study 2) and during the neonatal period (study 1). Insulin concentrations were measured using a radioimmunoassay kit (MP Biomedicals). Samples from each study were each measured within a separate assay and assay sensitivity averaged 0.61 and $0.39 \mu \mathrm{U} / \mathrm{mL}$ for the two studies. Mean intraassay coefficients of variability (CVs) based on two quality-control pools were $3.4 \%$ and $7.3 \%$, and $2.7 \%$ and $0.4 \%$, respectively. Interassay CVs were $3.4 \%$ and $5.3 \%$, respectively. Glucose concentrations for the two studies (each measured within a separate assay) were determined using the Glucose Oxidase Method (Pointe Scientific, Inc.) as described previously. Assay sensitivity was 5.9 and $4.5 \mathrm{mg} / \mathrm{dL}$, respectively. Intra-assay CVs were $1.2 \%$ and $0.5 \%(25 \mathrm{mg} / \mathrm{dL}$ QC pool), $1.2 \%$ and $0.5 \%$ (75 mg/dL QC pool), and $1.6 \%$ and $1.3 \%$ (150 mg/dL QC pool), and respective interassay CVs were $4.0 \%$, $0.6 \%$ and $0.9 \%$, respectively.

\section{4 | Bisphenol A measurements}

Free BPA (unconjugated) and total BPA were measured using a validated protocol published from the NIEHS-funded Round Robin study in one of the laboratories that participated in the study (Vandenberg et al., 2014). In brief, after thawing samples at room temperature, plasma or amniotic fluid $(0.5 \mathrm{~mL})$ was transferred to a $15 \mathrm{~mL}$ glass tube, and internal standards (d6-BPA and 13C12-BPA-G), ammonium acetate buffer, formic acid and Milli-Q water were added to a total volume of $3 \mathrm{~mL}$. An Oasis MCX cartridge (60 mg/3 mL; Waters) was used for the extraction and clean-up procedure. The cartridge was preconditioned with methanol and water. After loading the sample, the cartridge was washed with $15 \%$ methanol in water and eluted with methanol. The eluate was concentrated to $0.5 \mathrm{~mL}$. BPA levels in samples were quantified using a HPLC coupled with API 5500 ESI triplequadrupole mass spectrometer (ESI-MS/MS). Ten microliters of the extract was injected on to an analytical column (Betasil C18, $100 \times 2.1 \mathrm{~mm}$ column; Thermo Electron Corporation), which was connected to a Javelin guard column (Betasil C18, $20 \times 2.1 \mathrm{~mm}$ ). The mobile phase comprised methanol and $10 \mathrm{mM}$ ammonium acetate in water. The ESI-MS/MS was operated in the electrospray negative ion mode. Data were acquired using multiple reaction monitoring for the transitions of $227>212$ for BPA and $233>215$ for d6-BPA.

Quality-assurance and quality-control parameters included validation of the method by spiking internal standards into the sample matrices and passing through the entire analytical procedure to calculate recoveries of target analytes through the analytical method. A procedural blank was analyzed with the samples to check for interferences or laboratory contamination. The limit of detection (LOD) was $0.02 \mathrm{ng} / \mathrm{mL}$ for BPA. The recovery of d6-BPA spiked into samples was $95 \% \pm 29 \%$ (mean $\pm S D$ ). Reported concentrations were corrected for the recoveries of the surrogate standard (isotope dilution method). The native standards spiked into procedural blank and selected sample matrices and passed through the entire analytical procedure yielding recoveries of $105 \% \pm 5 \%$ and $102 \% \pm 7 \%$ for BPA, respectively. An external calibration curve was prepared by injecting $10 \mu \mathrm{L}$ of 0.01 $100 \mathrm{ng} / \mathrm{mL}$ certified BPA standards and the calibration coefficient was $>0.99$.

\section{5 | Validation study}

To determine if the sample collection procedure routinely used in the laboratory leaches BPA, three females were administered a single BPA dose $(0.5 \mathrm{mg} / \mathrm{kg}$ birth weight; s.c.). Two simultaneous plasma samples were collected before, and 6 and 24 hours after BPA administration using both a routine collection procedure (involving plastic instruments) and a plastic-free collection procedure. For the routine procedure, plastic syringes (BD) for blood extraction and plastic Pasteur pipettes (Fisher) for plasma transfer to storage plastic tube (DOT) sealed with a plastic cap (DOT) were used. For the plastic-free procedure, a vacutainer blood extraction system (BD) was used and blood was collected in a vacutainer glass tube (BD). Plasma was then transferred to a glass tube (Fisher) with a glass Pasteur pipette (Fisher). All samples were immediately frozen and stored at $-20^{\circ} \mathrm{C}$.

\section{6 | Statistical analysis}

Postnatal growth data were collected for 11 weeks in male offspring and 86 weeks ( 600 days) in female offspring. In the first analysis, birth weight and growth curves from birth to 11 weeks of age using all offspring (including both female and male animals) among treatment groups were analyzed. A linear random effect mixed model was used for both analyses to account for correlation between lambs born to the same mother and repeated measurements from the same offspring. Quadratic function was found to fit the growth curve well from birth to 11 weeks of age. A second analysis was then conducted to study long-term postnatal weight trajectories in female offspring, alone. Quadratic splines with knots at 3 and 6 months of age were used to fit the growth curve. For all the above analyses, all BPA dose groups were combined before comparing them to the controls.

For all analyses: to assess and adjust for sex differences, sex and treatment interaction was tested in each model; to adjust for litter size, numbers of female and male siblings in the same litter were included in the model. In addition, comparisons of fetal organ weights, fetal steroids and fetal hormonal measures were made using a regression model. Interactions between data collection time and gender (data collection and treatment) were assessed, within BPA-treated and control (male and female) groups, respectively.

Appropriate transformations were applied, as needed, to account for normality of data. Comparisons of fetal BPA concentrations (free and total) were analyzed using a mixed model with Tukey post-hoc tests with the number of fetuses as a covariate.

For the analysis of maternal steroidal measures and insulin-toglucose $(\mathrm{I} / \mathrm{G})$ ratio in study 2 , two-tailed $t$-test was performed. Comparisions for fetal I/G ratio were made between BPA vs. controls in each sex using the Mann-Whitney test. In addition, same sex fetuses born to the same dam were averaged within each group to account for 
dam effects. A univariate analysis of variance was used for comparing the newborn I/G ratio (study 1) and maternal weight gain.

Spearman's correlation analysis was performed to relate significant outcomes in study 2 with maternal/fetal BPA (free and total) levels. All statistics were run using PASW Statistics for Windows release 18.0.1 or SAS (Windows version 9.4) and all plots were generated using $R$ software. Differences were considered significant at $P<.05$. All data are presented as mean \pm SEM unless otherwise stated.

\section{3 | RESULTS}

The mean weight gains during pregnancy were 1.20, 1.36, 1.54 and $1.96 \mathrm{~kg}$ for the control, $\mathrm{BPA}_{\text {low, }} \mathrm{BPA}_{\text {medium }}$ and $\mathrm{BPA}_{\text {high }}$ respectively and did not differ significantly between control and BPA-treated groups ( $P=1.00$ for all three comparisons).

\section{1 | Study 1: Effects of prenatal bisphenol A on birth weight and early postnatal growth trajectory (0-11 weeks)}

Table 1A shows the mean birth weight for each treatment group by sex. As expected, the birth weights of female offspring were significantly lower compared with males $(P=.0023)$. There was no treatment effect on birth weight for either sex when the three BPAtreated groups were analyzed separately or combined. Growth trajectories from birth to 11 weeks of age are shown in Figure 1. Growth curves differed significantly between treatment groups and sex $(P<.0001)$, as described below. Despite the similarity in birth weight, the growth rate of BPA-treated males after birth (Figure 1, left panels) differed from controls. While control males grew $\sim 2.7 \mathrm{~kg} /$ week during week 1, prenatal BPA-treated males grew more slowly $(\sim 2.0 \mathrm{~kg} /$ week; $P=.0004)$. In control males, growth rates remained approximately the same during the subsequent 11 weeks. In contrast, the growth rate of BPA males increased over time $(P<.0001)$. By $\sim 6$ weeks of age, the BPA male growth rate approximated that of control males. By 10 weeks of age, BPA males grew faster than control males $(P=.0052$; Figure 1, left panels). Immediately after birth, control females grew $\sim 1.7 \mathrm{~kg} /$ week, while BPA females grew faster ( 2.1 kg/week; $P=.030$;

Figure 1, right panels). The growth rate increased with increasing age in both the control and BPA groups, but was less pronounced in BPA-treated females $(P<.001)$. By 10 weeks of age, growth rates in control and BPA females were similar.

Table 1B shows the I/G ratio in newborn lambs. There was no difference in the $\mathrm{I} / \mathrm{G}$ ratio between the BPA and control females $(P=.22$, .41 and .61 respectively, for $\mathrm{BPA}_{\text {low, }} \mathrm{BPA}_{\text {medium }}$ and $\mathrm{BPA}_{\text {high }}$ ) or males $(P=.91, .63$ and .99 respectively).

\subsection{Effects of prenatal bisphenol A on later growth trajectory (up to 86 weeks of age) in female offspring}

The weights of control and prenatal BPA-treated females from birth to 86 weeks of age are shown in Figure 2. As opposed to the increased
TABLE 1 Mean birth weight for each treatment group by sex and I/G ratio for each treatment group by sex in newborn lambs

$\begin{array}{lll} & \text { Female } & \text { Male } \\ & \text { Mean } \pm \text { SD } & \text { Mean } \pm \text { SD } \\ \text { Treatment group } & \mathrm{n} & \mathrm{n}\end{array}$

A, Mean birth weight for each treatment group by sex

\begin{tabular}{|c|c|c|c|}
\hline \multirow[t]{2}{*}{ BW (kg) } & \multirow[t]{2}{*}{ Control } & $6.22 \pm 1.44$ & $6.60 \pm 0.94$ \\
\hline & & 8 & 6 \\
\hline & Low & $5.88 \pm 1.02$ & $6.22 \pm 1.44$ \\
\hline & & 12 & 9 \\
\hline & Medium & $5.42 \pm 1.07$ & $6.36 \pm 1.66$ \\
\hline & & 13 & 13 \\
\hline & High & $5.90 \pm 1.42$ & $5.66 \pm 1.27$ \\
\hline & & 7 & 15 \\
\hline \multicolumn{4}{|c|}{$\mathrm{B}, \mathrm{I} / \mathrm{G}$ ratio for each treatment group by sex in newborn lambs } \\
\hline \multirow[t]{8}{*}{ I/G ratio } & Control & $0.20 \pm 0.06$ & $0.16 \pm 0.04$ \\
\hline & & 5 & 5 \\
\hline & Low & $0.13 \pm 0.04$ & $0.18 \pm 0.10$ \\
\hline & & 7 & 6 \\
\hline & Medium & $0.15 \pm 0.04$ & $0.20 \pm 0.09$ \\
\hline & & 10 & 7 \\
\hline & High & $0.16 \pm 0.11$ & $0.16 \pm 0.07$ \\
\hline & & 5 & 9 \\
\hline
\end{tabular}

BPA, bisphenol A; BW, birth weight; I/G, insulin-to-glucose ratio; $n$, number of lambs per group; SD, standard deviation.

BPA doses: $0.05,0.5$ or $5 \mathrm{mg} / \mathrm{kg} /$ day (referred to as: low, medium and high, respectively).

growth rate of BPA-treated females during the first few weeks, control females showed a higher growth rate compared with the BPAtreated group at 13 weeks of age. Growth rate was $2.98 \mathrm{~kg} /$ week in control vs. $2.76 \mathrm{~kg} /$ week in BPA-treated females $(P=.0029)$ at 13 weeks of age. At 26 weeks, growth rates had slowed in both groups (controls 0.77 vs. BPA $0.61 \mathrm{~kg} /$ week; $P=.0074$ ). By 80 weeks, growth rates for both groups were minimal and did not differ (controls 0.00 vs. BPA $0.1 \mathrm{~kg} /$ week; $P=.28$ ).

\section{3 | Study 2: Effect of prenatal bisphenol A on maternal fetal bisphenol A measures}

The mean unconjugated and total BPA concentrations in sheep cord blood, amniotic fluid and maternal circulation is shown in Figure 3. The majority of BPA in maternal and cord blood, as well as amniotic fluid was in the conjugated form (Figure $3 \mathrm{~A}$ vs. $3 \mathrm{~B}$ ) at both gestational time points. Concentrations of free and total BPA were significantly higher in BPA-treated groups compared with control groups in both maternal and fetal circulation (white asterisks). In general, free BPA concentrations were 10-fold lower in fetal circulation compared with maternal circulation at GD65 in both male and female fetuses 

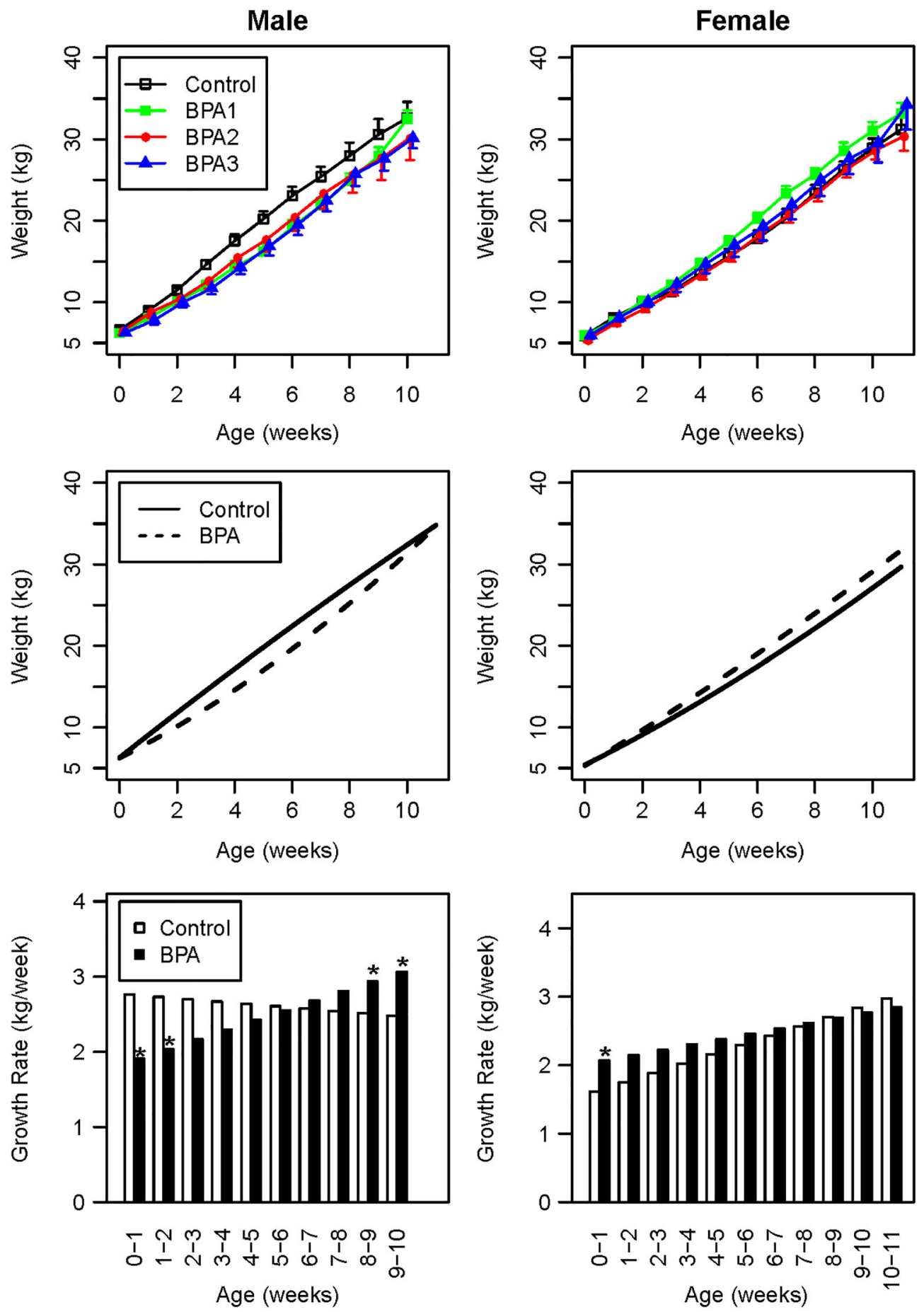

FIGURE 1 Growth trajectory and growth rate from birth to 11 weeks in males (left panels) and females (right panels) from control and BPA-treated groups. Top panels: means and standard errors of observed weight over time by treatment groups. Middle panels: estimated growth trajectories of the control and pooled BPA-treated groups based on the linear mixed effects model. Bottom panels: estimated weekly growth rate of the control and pooled BPA-treated groups, based on the linear mixed effect model. ${ }^{*} P<.05$ for comparing growth rate between control and pooled BPA-treated groups. BPA, bisphenol A [Colour figure can be viewed at wileyonlinelibrary.com]

(Figure 3A; a vs. b), but were comparable at GD90. Total BPA concentrations achieved were similar in maternal and fetal circulation at GD65 (Figure 3B). In contrast, total BPA concentrations achieved were twofold higher in both male and female fetal circulation and amniotic fluid compared with maternal circulation on GD90. Total
BPA concentrations in both male and female fetuses at GD90 were elevated compared with concentrations on GD65.

Focusing on sex differences, there were no differences in free BPA concentrations between male and female fetuses on GD65 or GD90 in the BPA-treated group, although in controls, higher concentrations of 


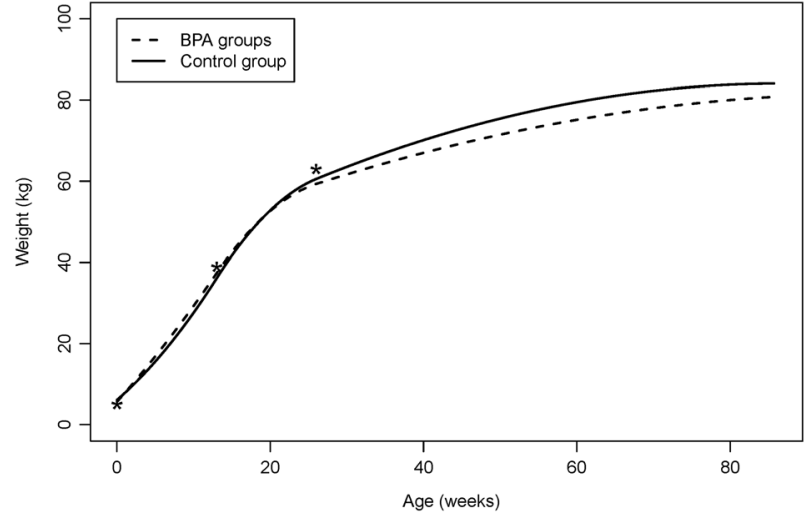

FIGURE 2 Weights from birth to 86 weeks for females in the control (solid black line) vs. all BPA groups combined (dashed line). *At birth, growth rate was $2.1 \mathrm{~kg} /$ week for BPA and $1.6 \mathrm{~kg} /$ week for controls, $P<.0001$; at 13 weeks, growth rate was $2.76 \mathrm{~kg} /$ week for BPA and $2.98 \mathrm{~kg} /$ week for controls, $P=.0029$; at 26 weeks, growth rate was $0.61 \mathrm{~kg} /$ week for BPA and $0.77 \mathrm{~kg} /$ week for controls, $P=.0074$. BPA, bisphenol A

BPA were evident in males compared with females on GD65 (Figure 3 $A$, gray diamond). In contrast, higher concentrations of total BPA were observed in BPA-treated males compared with females at GD65, but not GD90.

Validation studies in sheep provided no evidence of BPA contamination originating from any of the collection system used (Figure 4).

\section{4 | Effects of prenatal bisphenol A on hormones and metabolic measures}

No difference was observed between BPA vs. control group in maternal I/G ratio at GD65 (BPA $0.20 \pm 0.04$ vs. controls $0.18 \pm 0.05$ units) or at GD90 (BPA $0.20 \pm 0.05$ vs. controls $0.16 \pm 0.06$ ). Similarly, there was no difference between BPA vs. control groups in the fetal I/G ratio at GD65 (females $1.48 \pm 0.33$ vs. $9.10 \pm 14.69$; males $1.57 \pm 0.72$ vs.5.61 \pm 3.94 , respectively). At GD90, BPA-treated females tended to have a lower I/G ratio compared with controls (BPA $1.86 \pm 0.97$ vs. controls $4.76 \pm 2.44, P=.052$ ). No such difference was evident in males (BPA $1.8 \pm 0.54$ vs. controls $2.1 \pm 1.29$ ).

Maternal steroidal measures are summarized in Table S1 (see Supporting Information). Measures of DHEA, androstenedione, 17hydroxypregnenolone, 17-hydroxyprogesterone and testosterone were under the LOD for the assay used in both maternal and fetal samples. BPA treatment increased maternal corticosterone concentrations at day $65(P=.036)$ and pregnenolone level at GD90 $(P=.004)$. $\mathrm{DOC}$ in the maternal circulation tended to be higher at day 65 with BPA treatment. Fetal steroidal profiles are summarized in Table S2 (see Supporting Information). There was no significant interaction between sex and treatment at GD65 or GD90 (Table S2a; see Supporting Information). When comparing within treatment groups, progesterone and pregnenolone concentrations in females were significantly higher in the BPA compared with control females at GD65.
Interestingly, when comparing ratios of adrenal steroid precursors we noted increased ratios of progesterone to DOC in the BPA-treated females compared with control females at GD65 (Table S2b; see Supporting Information). Corticosterone and DOC were significantly lower in BPA females compared with control females at GD90, but similar differences were not seen between BPA and control male fetuses and there were no differences in adrenal steroid precursor ratios (Table S2b; see Supporting Information). Deoxycortisol and cortisol were also significantly lower in control females compared with control males at GD90. At GD90, BPA-treated males had significantly higher deoxycortisol than BPA females (Table S2b; see Supporting Information). Except from pregnenolone, which correlated with total BPA at day 65 in the female fetus $(R=0.683 P=.029)$, none of the other adrenal steroids that were significantly altered correlated with either free BPA or BPA.

\subsection{Effects of prenatal bisphenol A on fetal weight, size and organ weights}

Fetal body weight and anthropometric measurements are shown in Table 2. In the control group, no differences were observed in fetal body weight, head circumference or crown to rump length between females and males at GD65 or GD90. In BPA fetuses, males had larger body weights than females at GD90 ( $P=.008)$, but not at GD65 (Table 2). As expected, AGD was greater in males compared with females in both the control and BPA groups at both GD65 and GD90 (Table 2). The within-sex comparison of the control and BPA groups found that BPA males tended to have higher body weights compared with control males $(P=.061)$.

Organ/body weight ratios for heart, liver, thyroid and gonads are shown in Table 3 (other organ weights are summarized in Table S3; see Supporting Information). No significant differences were noted between sex when compared within each treatment group (Table 3); however, the heart/body weight ratio tended to be lower in control males compared with control females at GD65 ( $P=.091)$, the BPA males tended to have an increased heart/body weight ratio at GD90 $(P=.061)$ compared with BPA females.

Focusing on the BPA treatment effect within each sex, BPA females had a lower liver/body weight ratio relative to the control group ( $P=.023$ ) at GD90 (Table 3). Similar differences were not observed in BPA males at both gestational ages. In contrast, BPA males had a higher heart/body weight ratio compared with controls $(P=.030)$ at GD90 (Table 3). No differences in gonadal (ovary or testis)/body weight ratios were evident between the control and BPA groups at both gestational time points.

A significant increase in the thyroid/body weight ratio was evident in BPA males compared with controls at GD65 $(P=.028)$ (Table 3). There were no other differences in the organ/body weight ratio with lungs, pancreas, kidney, adrenal and pituitary (Table S3; see Supporting Information). Spearman correlation analysis revealed no significant correlation between the organ weight/body weight ratio for heart, liver and with either free or total BPA. 
Maternal

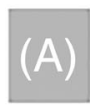

GD 65

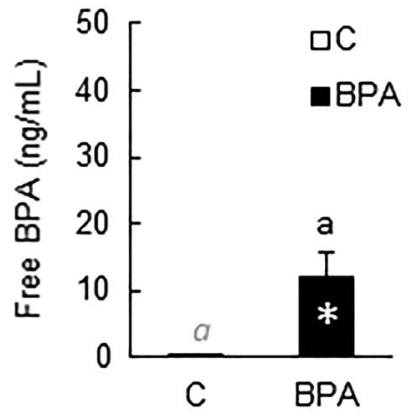

GD 90
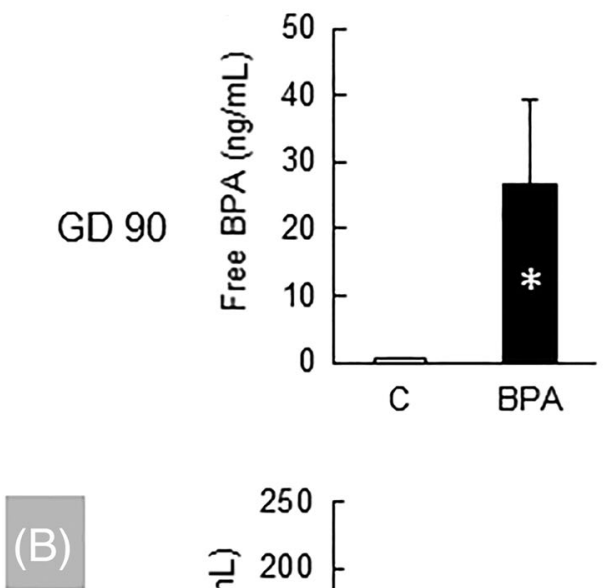

GD 65
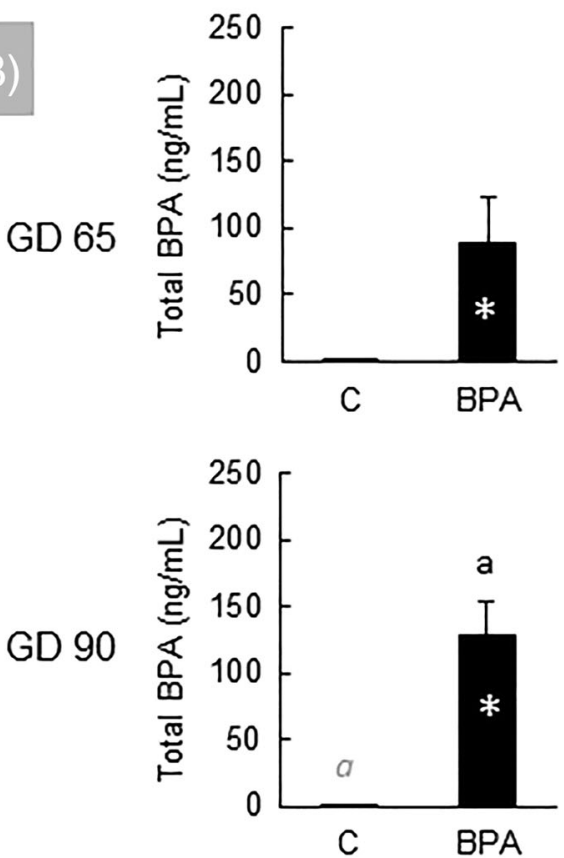

Fetal
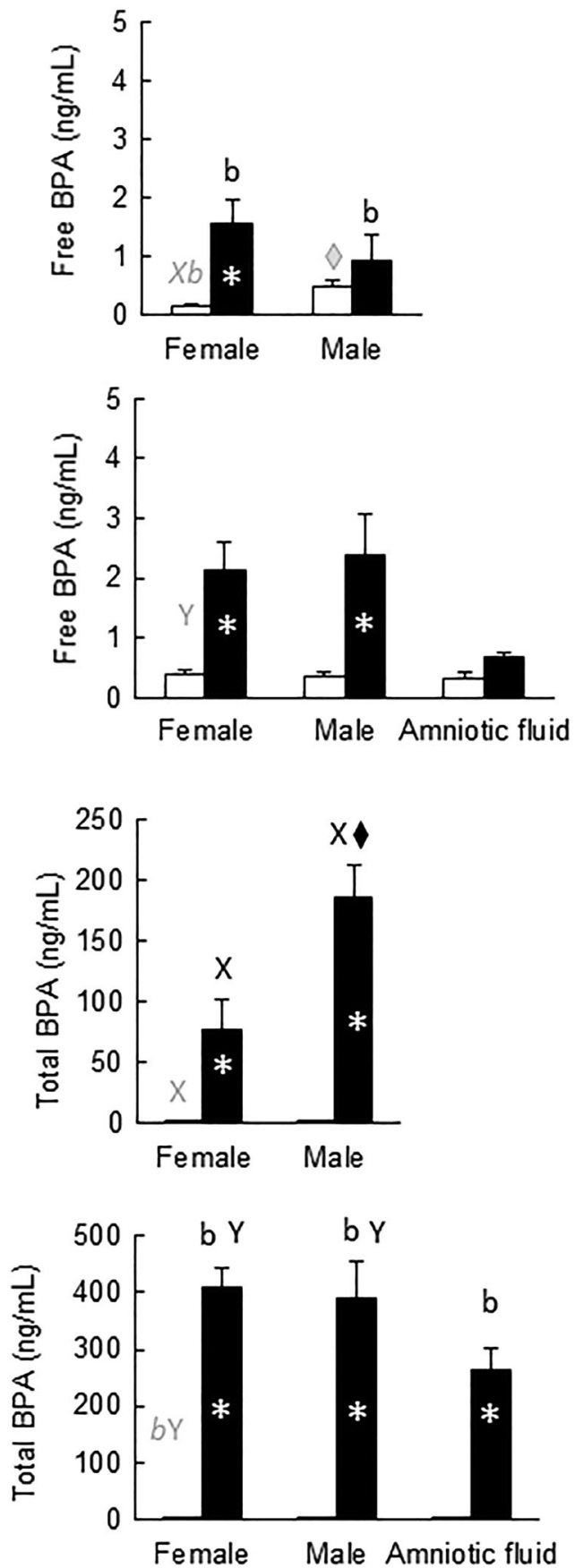

FIGURE 3 A, Free BPA. B, Total BPA. Mean $( \pm$ SEM) concentrations of free and total BPA in maternal blood (left) and umbilical artery blood and amniotic fluid (right) and samples at gestational day 65 (top) and 90 (bottom) in C (open bars) and BPA-treated (closed bars) groups. White Asterisks denote significant difference between $\mathrm{C}$ and BPA for each category. Diamond symbol (C: gray; black: BPA group) symbol indicate male vs. female differences in BPA levels at each time point. a vs. b indicate differences between maternal vs. fetal levels of BPA achieved (C: gray; black: BPA group). X vs. Y (C: gray; black: BPA group) indicate differences in BPA levels achieved between days 65 and 90 within each category for each sex. BPA, bisphenol A; C, control; GD, gestational day

\section{4 | DISCUSSION}

To our knowledge, this study is the first to assess the sex-specific effects of gestational BPA exposure on fetal anthropometrics and postnatal growth trajectory in a precocial mammalian model, which reveals significant sex-by-treatment interactions. Gestational BPA led to the sexually dimorphic effects on fetal organ weights, with liver weight affected in females in contrast to heart and thyroid weights in males. Sex differences were also evident in early postnatal growth trajectories with BPA males growing more slowly than controls during the early postnatal period followed by catch-up growth, while BPA females showed increased growth early on followed by the slowing 

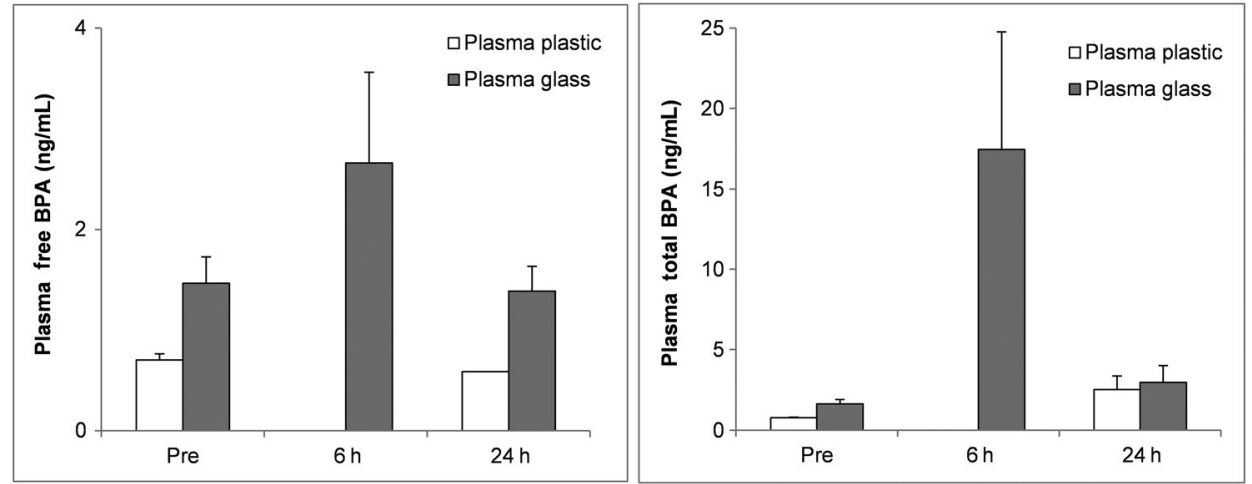

FIGURE 4 BPA validation study. Three sheep females were administered a single BPA dose ( $0.5 \mathrm{mg} / \mathrm{kg}$ birth weight, s.c.) was administered to each female. Two simultaneous plasma samples were collected before, 6 and $24 \mathrm{~h}$ after the BPA dose using both a routine collection procedure (involving use of plastic instruments) and a plastic-free collection procedure. BPA, bisphenol A

TABLE 2 Anthropometric measurements of fetuses: Comparing BPA ( $0.5 \mathrm{mg} / \mathrm{kg}$ dose) vs. control within each sex and comparing male vs. female within each treatment group at GD65 and GD90

\begin{tabular}{|c|c|c|c|c|c|}
\hline & \multirow[b]{2}{*}{ GD } & \multicolumn{2}{|l|}{ Female } & \multicolumn{2}{|l|}{ Male } \\
\hline & & $\begin{array}{l}\text { Control } \\
\text { Mean } \pm \text { SD } \\
n\end{array}$ & $\begin{array}{l}\text { BPA } \\
\text { Mean } \pm \text { SD } \\
n\end{array}$ & $\begin{array}{l}\text { Control } \\
\text { Mean } \pm \text { SD } \\
n\end{array}$ & $\begin{array}{l}\text { BPA } \\
\text { Mean } \pm \text { SD } \\
n\end{array}$ \\
\hline FW (g) & $\begin{array}{l}65 \\
90\end{array}$ & $\begin{array}{c}126.67 \pm 18.7 \\
9 \\
662.5 \pm 97.1 \\
8\end{array}$ & $\begin{array}{c}124.44 \pm 21.3 \\
9 \\
647.78 \pm 32.3^{\mathrm{a} *} \\
9\end{array}$ & $\begin{array}{c}143.33 \pm 36.7 \\
6 \\
653 \pm 45.5 \\
10\end{array}$ & $\begin{array}{l}140 \pm 17.9 \\
11 \\
715 \pm 59.2^{\mathrm{b} *} \\
4\end{array}$ \\
\hline $\mathrm{HC}(\mathrm{cm})$ & $\begin{array}{l}65 \\
90\end{array}$ & $\begin{array}{c}13.31 \pm 1.1 \\
9 \\
21.34 \pm 0.8 \\
8\end{array}$ & $\begin{array}{c}13.3 \pm 0.8 \\
9 \\
21.27 \pm 0.9 \\
9\end{array}$ & $\begin{array}{c}13.17 \pm 0.6 \\
6 \\
21.15 \pm 0.7 \\
10\end{array}$ & $\begin{array}{c}13.76 \pm 1.1 \\
11 \\
21.58 \pm 0.6 \\
4\end{array}$ \\
\hline $\mathrm{CR}(\mathrm{cm})$ & $\begin{array}{l}65 \\
90\end{array}$ & $\begin{array}{c}16.18 \pm 1.6 \\
9 \\
27.91 \pm 1.3 \\
8\end{array}$ & $\begin{array}{c}16.14 \pm 1.5 \\
9 \\
27.64 \pm 0.9 \\
9\end{array}$ & $\begin{array}{c}15.82 \pm 1.4 \\
6 \\
27.17 \pm 1.4 \\
10\end{array}$ & $\begin{array}{c}16.38 \pm 1.5 \\
11 \\
26.93 \pm 3.9 \\
4\end{array}$ \\
\hline
\end{tabular}

AGD, anogenital distance; BPA, bisphenol A; CR, crown to rump; FW, fetal weight; GD, gestational day; HC, head circumference; $n$, number of lambs per group; SD, standard deviation. $a \neq b$ denotes differences between sex within treatment groups $P<.05 . A \neq B$ denotes differences between treatment groups within sex, $P<.05$.

${ }^{*} P$ value adjusted for no. of fetuses per ewe. FW day 90 BPA female vs. BPA male $P=.008$, AGD for control male vs. female at GD65 and GD90, $P \leq .001$. AGD for BPA male vs. female at GD65 and GD90, $P \leq .001$.

of growth. Although the contribution of sexually dimorphic differences in fetal concentrations of total BPA achieved on GD65 following gestational BPA exposure remains unclear, the relevance of the sexspecific impact of BPA on fetal organ weights, steroidal profiles and growth trajectories are discussed below.

\subsection{Maternal and fetal concentrations of bisphenol A}

Consistent with the transplacental transfer of BPA seen in earlier studies (Balakrishnan, Henare, Thorstensen, Ponnampalam, \& Mitchell,
2010; Gingrich et al., 2019; Ikezuki et al., 2002; Schonfelder et al., 2002), we observed transplacental transfer of BPA to the fetus with measurable concentrations of free BPA detectable in umbilical cord blood. In this assessment of chronic BPA exposure at two time points during pregnancy (GD65 and GD90 of a 147-day gestation pregnancy), concentrations of free and total BPA in maternal circulation were comparable between GD65 and GD90, indicative of the short half-life and fast clearance of BPA reported in earlier studies (Collet et al., 2010; Gingrich et al., 2019; Viguie et al., 2013) and supportive of a lack of an accummulation of BPA in the maternal compartment after chronic BPA exposure. Maternal and umbilical cord 
TABLE 3 Fetal organ weights: Comparing BPA $(0.5 \mathrm{mg} / \mathrm{kg}$ dose $)$ vs. control within each sex and comparing male vs. female within each treatment group at GD65 and GD90

\begin{tabular}{|c|c|c|c|c|c|}
\hline \multirow[b]{2}{*}{ Ratios } & \multirow[b]{2}{*}{ GD } & \multicolumn{2}{|l|}{ Female } & \multicolumn{2}{|l|}{ Male } \\
\hline & & $\begin{array}{l}\text { Control } \\
\text { Mean } \pm \text { SD } \\
n\end{array}$ & $\begin{array}{l}\text { BPA } \\
\text { Mean } \pm \text { SD } \\
n\end{array}$ & $\begin{array}{l}\text { Control } \\
\text { Mean } \pm \text { SD } \\
n\end{array}$ & $\begin{array}{l}\text { BPA } \\
\text { Mean } \pm \text { SD } \\
n\end{array}$ \\
\hline Heart/body weight ${ }^{a}$ & $\begin{array}{l}65 \\
90\end{array}$ & $\begin{array}{c}0.909 \pm 0.228 \\
9 \\
0.836 \pm 0.089 \\
8\end{array}$ & $\begin{array}{c}0.826 \pm 0.129 \\
9 \\
0.824 \pm 0.073 \\
9\end{array}$ & $\begin{array}{l}0.750 \pm 0.063 \\
6 \\
0.852 \pm 0.075^{\mathrm{B}^{*}} \\
10\end{array}$ & $\begin{array}{l}0.782 \pm 0.085 \\
11 \\
0.983 \pm 0.126^{A^{*}} \\
4\end{array}$ \\
\hline Liver/body weight ${ }^{a}$ & $\begin{array}{l}65 \\
90\end{array}$ & $\begin{array}{l}6.822 \pm 0.828 \\
9 \\
5.129 \pm 0.495^{B^{*}} \\
8\end{array}$ & $\begin{array}{l}6.501 \pm 0.568 \\
9 \\
4.895 \pm 0.329^{A^{*}} \\
9\end{array}$ & $\begin{array}{c}6.407 \pm 0.785 \\
6 \\
4.993 \pm 0.639 \\
10\end{array}$ & $\begin{array}{c}6.220 \pm 0.576 \\
11 \\
5.307 \pm 0.783 \\
4\end{array}$ \\
\hline Thyroid/body weight ${ }^{\mathrm{a}}$ & $\begin{array}{l}65 \\
90\end{array}$ & $\begin{array}{c}0.051 \pm 0.024 \\
9 \\
0.038 \pm 0.015 \\
8\end{array}$ & $\begin{array}{c}0.040 \pm 0.013 \\
9 \\
0.041 \pm 0.009 \\
9\end{array}$ & $\begin{array}{l}0.045 \pm 0.010 \\
6 \\
0.040 \pm 0.008^{\mathrm{B}^{*}} \\
10\end{array}$ & $\begin{array}{l}0.035 \pm 0.012 \\
11 \\
0.052 \pm 0.011^{\mathrm{A}^{*}} \\
4\end{array}$ \\
\hline
\end{tabular}

BPA, bisphenol A; GD, gestational day; SD, standard deviation.

${ }^{a}$ Adjusted for body weight, then multiplied by $100 . A \neq B$ denotes differences between treatment groups within sex, $P<.05$.

${ }^{b}$ Ovaries in females and testes in males.

${ }^{*} P$ value adjusted for no. of fetuses per ewe. Female liver BPA vs. control $P=.023$, male heart BPA vs. control $P=.03$, thyroid, $P=.028$

concentrations of BPA achieved following the daily subcutaneous administration of an environmentally relevant dose of BPA have not previously been studied in detail. One study investigating the pharmacokinetics of BPA in fetal plasma following single maternal intravenous infusion of $1 \mathrm{mg} / \mathrm{kg}$ of BPA in sheep found concentrations approaching $90 \mathrm{ng} / \mathrm{mL} 1$ hour postinjection (Gauderat et al., 2017). Maternal concentrations of free BPA achieved in the present study, averaging 12.2 and $26.5 \mathrm{ng} / \mathrm{mL}$ respectively at GD65 and GD90, are within the the range reported in a Korean study (range 0.44$47.1 \mathrm{ng} / \mathrm{mL}$ ) (Lee et al., 2018) and our Michigan-based study during the first trimester $(<L O D$ to $96.43 \mathrm{ng} / \mathrm{mL})$ and at term $(<L O D$ to $89.60 \mathrm{ng} / \mathrm{mL}$ ) (Veiga-Lopez, Kannan, et al., 2015). Umbilical cord blood concentrations of $\sim 2 \mathrm{ng} / \mathrm{mL}$ of free BPA, achieved in the present study at both GD65 and GD90 following daily s.c. administration of $0.5 \mathrm{mg} / \mathrm{kg} /$ day BPA, are also within the range of free BPA found in mid-gestation umbilical cord blood concentrations (<LOD $52.26 \mathrm{ng} / \mathrm{mL}$ ) in a California-based study (Gerona et al., 2013), at term cord blood concentrations ( $<$ LOD $51.5 \mathrm{ng} / \mathrm{mL}$ ) in the Korean study (Lee et al., 2018) and in our Michigan-based study (<LOD $41.83 \mathrm{ng} / \mathrm{mL}$ ) (Veiga-Lopez, Kannan, et al., 2015).

Comparative estimates of free and total BPA in the cord blood of humans are limited. The umbilical cord concentrations of BPA glucuronide in the California study (<LOD $3.05 \mathrm{ng} / \mathrm{mL}$ ) and our human Michigan study (<LOD 4.85 ng/mL) (Gerona et al., 2013; Veiga-Lopez, Kannan, et al., 2015) are much lower than the free BPA concentrations. In contrast, total BPA concentrations are higher than free BPA in our sheep study. In addition, in the present study, the ratio of free-to-total BPA is much lower in umbilical and aminiotic fluid compared with that seen in maternal circulation. The high presence of total BPA over free BPA in the sheep study indicates that the fetal-placental unit is efficient in metabolizing BPA into its conjugated form, and that conjugated metabolites appear to accumulate in the fetal placental compartment. High concentrations of accumulated conjugated BPA in the sheep fetus have been reported following a single intravenous infusion of BPA (Corbel et al., 2013). As BPA has been shown to be de-conjugated in the liver, these findings suggest that enzymes required for de-conjugation and elimination of BPA may not be fully functional in the fetal liver (Coughtrie, Burchell, Leakey, \& Hume, 1988). The sex differences in levels of BPA achieved at GD90 may reflect differences in metabolism/clearance of BPA between males and females. Accumulation of conjugated BPA in the fetal compartment may have physiological relevance, as BPA glucuronide has also been reported to be biologically active (Boucher, Boudreau, Ahmed, \& Atlas, 2015). Finally, the validation study we have conducted negates the concern that some of the measured BPA reflects processing contamination.

\subsection{Prenatal bisphenol A programming of organogenesis and fetal growth}

There are limited epidemiological studies addressing the association of prenatal BPA exposure on organogenesis and/or fetal health. Most 
human studies have focused on birth outcomes as the endpoint of prenatal exposure to BPA. A recent study noted that elevated maternal concentrations of BPA in mid-late gestation were correlated with impaired fetal growth and head circumference (Snijder et al., 2013). Interestingly, sex differences in birth outcomes of maternal BPA exposure have been reported in a recent study, with elevated risk for largefor-gestational age, as well as small-for-gestational age male neonates depending on exposure dose of BPA. Similar effects on birth weight were not evident in female offspring (Chou et al., 2011). Interestingly, BPA-treated male fetuses were found to be also heavier than BPAtreated females at GD90 in the present study, possibly reflecting the increased concentrations of total BPA found in GD65 males.

Lack of effect of prenatal BPA treatment on birth weight at all doses in study 1 differs from that of our previous study where we found that prenatal BPA ( $5 \mathrm{mg} / \mathrm{kg} /$ day) resulted in decreased body weight of female fetuses (Savabieasfahani et al., 2006). These differences may reflect changes in environmental conditions. Epidemiological studies investigating the association of BPA with birth weight are also inconsistent, with some studies reporting a reduction (Burstyn et al., 2013; Miao, Yuan, Zhu, He, \& Li, 2011; Snijder et al., 2013) or no change (Padmanabhan et al., 2008), while others report an increase (Lee et al., 2008) or U-shaped response curve (Philippat et al., 2012). These discrepancies in birth weight variability could be explained by both the exposure and timing of BPA exposure during pregnancy and interaction with other environmental exposures, diet and/or lifestyle factors.

In contrast to the lack of effects on birth weight, significant sexand time-specific effects of prenatal BPA treatment, although not directly correlated, were evident in the organs involved in cardiometabolic function. In females, this is manifested by decreased fetal liver weight at GD90. The lower levels of total BPA in female GD65 fetuses compared with males in the face of reduced liver weight suggest female fetuses may metabolize BPA quicker than males. Available evidence indicates BPA accumulates in human fetal liver and elevated BPA is associated with adult liver dysfunction (Lee et al., 2014; Nahar, Kim, Sartor, \& Dolinoy, 2014; Nahar, Liao, Kannan, Harris, \& Dolinoy, 2015). While studies addressing causal relationships between prenatal exposure to BPA on postnatal programming of human liver are not feasible, animal studies show that developmental exposure to BPA induces alterations in hepatic gene expression and diseases such as hepatic steatosis, liver tumors and metabolic syndrome (DeBenedictis, Guan, \& Yang, 2016; Moustafa \& Ahmed, 2016; Wei et al., 2014); e.g., prenatal BPA from embryonic day 7.5 to 18.5 in mice affects liver maturation in a sex-specific fashion with effects seen only in females (DeBenedictis et al., 2016). Another study also found exposure to BPA $25 \mu \mathrm{g} / \mathrm{kg} /$ day from GD8 through postnatal day 16, increased hepatic lipid content in 5- and 39-week-old females, but not male mice (Shimpi et al., 2017). Other animal studies exploring the impact of BPA on liver focused on either of the sexes; e.g., a study focusing on male offspring noted that, at exposure to $50 \mathrm{mg} / \mathrm{kg} /$ day BPA from GDO to the end of lactation at postnatal day 21 , results showed abnormalities of liver function and hepatic damage in male rats (Xia et al., 2014). Similarly, prenatal BPA treatment was found to program fatty liver disease in male offspring when subjected postnatally to a high-fat diet (Wei et al., 2014). In contrast, a study in mice focusing on female offspring showed that exposure to 50 and $200 \mathrm{mg} / \mathrm{kg}$ birth weight BPA from the beginning of gestation through 3 months postweaning increased vacuolation of hepatic cells, proliferation of Kupffer cells and altered liver enzymes in females (Moustafa \& Ahmed, 2016). The decrease in fetal female liver weight seen in our study reflecting early programming effects may contribute to later metabolic dysfunctions.

As opposed to lack of effect of prenatal BPA on fetal male liver, prenatal BPA treatment increased the heart/body weight ratio at GD90 in males, alone. Consistent with the lack of effect on the female heart during fetal life, there were no effects of prenatal BPA treatment on blood pressure or morphometric measures in adult BPA-treated offspring (Koneva et al., 2017; MohanKumar et al., 2017). However, prenatal BPA treatment upregulated several genes involved in the regulation of myocardium growth, heart development and remodeling, and the downregulation of genes involved in cellular respiration and inflammation in adult prenatal BPA-treated females (Koneva et al., 2017). Prenatal BPA treatment was also found to reduce collagen expression in the right ventricle (MohanKumar et al., 2017). These changes have the potential to lead to cardiac compromise with adult aging. The changes in fetal heart weight, while not correlating with measured BPA levels, may serve as proxy for later functional defects that may develop in the male. Cardiac-specific studies have not been carried out in adult, prenatal BPA-treated rams. In our studies, males were not maintained in parallel with females.

The male-specific effect of prenatal BPA on the thyroid, an important regulator of metabolic functions, including hepatic steatosis (Mullur, Liu, \& Brent, 2014), is of interest. Our findings of increased thyroid weight in prenatally treated BPA male fetuses, coupled with recent findings in sheep that prenatal BPA treatment induces disruption of fetal thyroid function (Guignard et al., 2017), raises the possibility that prenatal exposure to BPA may compromise thyroid function in adulthood. This does not hold true with females, as thyroid gland size was not affected (this study). EDCs have been shown to affect thyroid function (Miller, Crofton, Rice, \& Zoeller, 2009). BPA in particular has been shown to affect thyroid volume (BPA concentrations inversely associated with thyroid volume) and affect thyroid function in human studies (Meeker \& Ferguson, 2011; Wang et al., 2015; Zoeller, 2007). Prenatal exposure to BPA at around the third trimester of pregnancy has been shown to affect the offspring thyroid axis in a sex-specific pattern, with conflicting data in one study showing elevated BPA correlated with low thyroid-stimulating hormone in male neonates and others showing the same pattern in female neonates (Chevrier et al., 2013; Romano et al., 2015). Similarly in rodent studies, there are conflicting data on the sex-specific effects of BPA on the thyroid gland with effects seen in both sexes vs. male alone vs. no effect on either sex (Kobayashi et al., 2005; Xu et al., 2007; Zoeller, Bansal, \& Parris, 2005). Prenatal BPA exposure is shown to alter thyroid hormone in sheep; however, this effect was not sex specific and there was no mention on fetal thyroid organ weight (Viguie et al., 2013). As the thyroid has been shown to have a critical role in 
fetal and postnatal growth (Shields, Knight, Hill, Hattersley, \& Vaidya, 2011; Smallridge \& Ladenson, 2001), further studies to assess the functional effects of this sex-specific pattern of change in size of thyroid gland are warranted.

Interestingly, while we saw sex-specific effects of BPA on fetal organ weights we did not see sex differences in fetal organ weights. To what extent these sex-specific effects of BPA have on organ systems are key to cardiometabolic function are the result of masculinization or defeminization of systems is an important line of research. Our studies found no effect of BPA on AGD, a biomarker for masculinization at GD65 and GD90 in both sexes, although the expected increase in AGD was evident in the males at GD65 and GD90 compared with females in both control and BPA-treated groups. In contrast, an earlier study found prenatal BPA exposure reduced AGD in male offspring (Mammadov, Uncu, \& Dalkan, 2018; Miao et al., 2011).

\section{3 | Prenatal bisphenol A and maternal/fetal steroidogenesis and metabolic measures}

Because steroid hormones can program fetal growth and adult phenotype, and BPA has been shown to influence steroidogenesis (Peretz et al., 2014), we investigated the impact of prenatal BPA treatment on maternal and fetal steroidogenesis. Lack of effect of prenatal BPA treatment on maternal and fetal estrogens may suggest the programming of adult reproductive and metabolic dysfunction by prenatal BPA treatment (Alonso-Magdalena, Quesada, \& Nadal, 2015) are not mediated via changes in maternal and fetal estrogens. However, we did note a significant increase in corticosterone in the BPA-treated mothers at GD65, but not at GD90. In general, maternal stress raises corticosterone concentrations during pregnancy with negative effects on a feto-placental unit (Jafari, Mehla, Afrashteh, Kolb, \& Mohajerani, 2017; Vaughan, Sferruzzi-Perri, \& Fowden, 2012). Elevations in corticosterone rather than cortisol concentrations strongly correlate with fetal stress in human studies (Wynne-Edwards, Edwards, \& Hancock, 2013). Despite elevated corticosterone in maternal circulation, corticosterone and DOC, which are both downstream products in the adrenal steroidal pathway leading to aldosterone synthesis, were lower in the D90 BPA-exposed female fetuses. While similar changes in corticosterone and DOC levels were not seen in the GD65 BPAexposed female fetuses, higher levels of pregnenolone and progesterone, upstream products of the aldosterone synthetic pathway and a higher progesterone/DOC ratio were evident. These findings could be suggestive of a fetal compensatory response to overcome inhibition of adrenal enzyme activity upstream (e.g., CYP21) of the aldosterone synthesis pathway. Owing to multiple precursors being below the level of detection, similar assessment of cortisol and androgen pathways were not possible. A recent in vitro study with a human cell line found BPA altered adrenal steroidogenesis by inhibiting CYP17 (Zhang et al., 2011) and, similar to our study, noted an increase in progesterone and a decrease in downstream steroidal hormone levels. One possibility is prenatal BPA-blocked CYP17 activity leading to unmeasurable downstream steroidal products.
In epidemiological studies, BPA exposure has been shown to be associated with type 2 diabetes (Lang et al., 2008). In rodent models, prenatal BPA has been shown to lead to insulin resistance in the male offspring (Alonso-Magdalena et al., 2015). Our group has previously shown that female offspring exposed to prenatal BPA also develop reduced insulin sensitivity in adulthood (Veiga-Lopez et al., 2016). To our knowledge, this is the first study to assess insulin sensitivity in fetal circulation at early and later gestation in both sexes. A trend for increased insulin sensitivity only in the BPA-treated female fetus at GD90 in the absence of such differences in the maternal or newborn circulation may be a reflection of early programming effects of BPA on insulin homeostasis (Veiga-Lopez et al.,2016). Lack of effect of BPA on maternal insulin sensitivity suggests that the effects of BPA on the insulin sensitivity of adult offspring are programmed indirectly via other maternal mechanisms or through direct effects at the fetal level.

\subsection{Prenatal bisphenol A programming of sexually-dimorphic postnatal growth trajectory}

A significant sex difference was evident in early postatal growth trajectory of prenatal BPA-treated offspring, independent of the BPA dose. Prenatal BPA-treated female lambs grew faster immediately after birth with slowing of growth velocity over time compared with their control counterparts. In contrast, prenatal BPA-treated males grew slower in the immediate postnatal period, but had an increased growth rate over time compared with the control group. Such sex differences in growth trajectories may be related to higher concentrations of total BPA found in male fetuses during early gestation (GD65). While the relative biological potency of conjugated BPA is unknown, there is some evidence for bioactivity of the glucuronide form of BPA (Boucher et al., 2015). Native steroids such as estrogen, when conjugated with bovine serum albumin have the capability to stimulate surface receptors leading to rapid signaling (Chen et al., 2017; Watson, Hu, \& Paulucci-Holthauzen, 2014). Considering the estrogenic properties of BPA, it is conceivable the same holds true for the conjugated form of BPA.

Low birth weight followed by rapid catch-up weight gain have been shown to lead to adverse cardiometabolic phenotype in adulthood (Barker, 2004). Although we did not see low birth weight in our cohort, the female offspring did show a brief period of increased weight gain soon after delivery. One epidemiological study reported larger increases in body mass index slope from 2 to 5 years associated with higher BPA with association being stronger in girls, while another found girls exposed to higher concentrations of prenatal BPA have lower body mass index in childhood (Braun et al., 2014; Harley et al., 2013). The increased growth rate evidenced in our study may contribute to the insulin resistance and increase in adipocyte size and inflammatory markers evidenced in adult prenatal BPA-treated sheep (Veiga-Lopez et al., 2016). The implication of the initial slower trajectory of postnatal weight gain followed by increased weight gain velocity later in males needs to be explored further, as several other factors 
such as environmental exposure to other ubiquitously present environmental chemicals and their interaction with diet could also be playing a role. Considering that low birth weight followed by catch-up growth has been shown to lead to cardiometabolic diseases later in life (Barker, 2004; Valsamakis et al., 2006), the enhanced growth rate in the absence of change in birth weight is also a potential risk factor.

Finally, the major strengths of our current study assessing the impact of prenatal BPA on fetal and postnatal health of the offspring are: (1) use of sheep as the precocial species, which have a similar developmental trajectory as humans; (2) use of three different doses of BPA spanning environmental to occupational exposure concentrations; (3) measurement of both free and total BPA concentrations using a well validated assay (Vandenberg et al., 2014; Veiga-Lopez, Kannan, et al., 2015) at two different time points in fetal and maternal serum allowing exploration of the contribution of a time-specific impact of BPA; (4) use of LCMS for measures of steroid hormones allowing for improved accuracy of steroid measures; and (5) more importantly, to the best of our knowledge, the first longitudinal study of assessment of the sex-specific impact of prenatal BPA on growth trajectory. Study limitations include lack of follow-up of the male offspring beyond 11 weeks of age in parallel with the female offspring, a necessity to avoid unwanted pregnancy in our cohort, and absence of information on adult male phenotype to relate these early findings.

In conclusion, this study documents internal concentrations of maternal and fetal BPA achieved at two time points in gestation following the treatment of pregnant sheep with environmentally relevant doses of BPA. Importantly, the study demonstrates sexually dimorphic effects of prenatal BPA on organogenesis and early postnatal growth trajectory-aspects of relevance to the programming of adult reproductive and metabolic dysfunctions-in the absence of major disruptions in the maternal/fetal steroid hormone milieu.

\section{FUNDING SOURCES}

Research reported in this publication was supported by the National Institute of Environmental Health Sciences of the National Institute of Health R01 ES016541 to VP and R01ES027863 to AV-L.

\section{CONFLICT OF INTEREST}

The authors have no conflict of interest to report.

\section{ORCID}

Arpita Kalla Vyas (1) https://orcid.org/0000-0002-6256-5838

\section{REFERENCES}

Abi Salloum, B., Steckler, T. L., Herkimer, C., Lee, J. S., \& Padmanabhan, V. (2013). Developmental programming: impact of prenatal exposure to bisphenol-A and methoxychlor on steroid feedbacks in sheep. Toxicology and Applied Pharmacology, 268(3), 300-308. https://doi.org/ 10.1016/j.taap.2013.02.011

Alonso-Magdalena, P., Quesada, I., \& Nadal, A. (2015). Prenatal exposure to BPA and offspring outcomes: the diabesogenic behavior of BPA. DoseResponse: A Publication of International Hormesis Society, 13(2), 1-8. 1559325815590395. https://doi.org/10.1177/1559325815590395
Balakrishnan, B., Henare, K., Thorstensen, E. B., Ponnampalam, A. P., \& Mitchell, M. D. (2010). Transfer of bisphenol A across the human placenta. American Journal of Obstetrics and Gynecology, 202(4), 393. e1-393.e7. https://doi.org/10.1016/j.ajog.2010.01.025

Barker, D. J. (2004). The developmental origins of adult disease. Journal of the American College of Nutrition, 23(6 Suppl), 588S-595S. https://doi. org/10.1080/07315724.2004.10719428

Beronius, A., Ruden, C., Hakansson, H., \& Hanberg, A. (2010). Risk to all or none? A comparative analysis of controversies in the health risk assessment of Bisphenol A. Reproductive Toxicology, 29(2), 132-146. https:// doi.org/10.1016/j.reprotox.2009.11.007

Bloom, M. S., Mok-Lin, E., \& Fujimoto, V. Y. (2016). Bisphenol A and ovarian steroidogenesis. Fertility and Sterility, 106(4), 857-863. https://doi. org/10.1016/j.fertnstert.2016.08.021

Boucher, J. G., Boudreau, A., Ahmed, S., \& Atlas, E. (2015). In vitro effects of bisphenol A beta-D-glucuronide (BPA-G) on adipogenesis in human and murine preadipocytes. Environmental Health Perspectives, 123(12), 1287-1293. https://doi.org/10.1289/ehp.1409143

Braun, J. M., Lanphear, B. P., Calafat, A. M., Deria, S., Khoury, J., Howe, C. J., \& Venners, S. A. (2014). Early-life bisphenol a exposure and child body mass index: a prospective cohort study. Environmental Health Perspectives, 122(11), 1239-1245. https://doi.org/10.1289/ehp.1408258

Burstyn, I., Martin, J. W., Beesoon, S., Bamforth, F., Li, Q., Yasui, Y., \& Cherry, N. M. (2013). Maternal exposure to bisphenol-A and fetal growth restriction: a case-referent study. International Journal of Environmental Research and Public Health, 10(12), 7001-7014. https://doi. org/10.3390/ijerph10127001

Calafat, A. M., Weuve, J., Ye, X., Jia, L. T., Hu, H., Ringer, S., \& Hauser, R. (2009). Exposure to bisphenol $A$ and other phenols in neonatal intensive care unit premature infants. Environmental Health Perspectives, 117(4), 639-644. https://doi.org/10.1289/ehp.0800265

Chen, X., Wang, Y., Xu, F., Wei, X., Zhang, J., Wang, C., ... Wang, Q. (2017). The rapid effect of bisphenol-A on long-term potentiation in hippocampus involves estrogen receptors and ERK activation. Neural Plasticity, 2017, 5196958; 9 https://doi.org/10.1155/2017/5196958

Chevrier, J., Gunier, R. B., Bradman, A., Holland, N. T., Calafat, A. M., Eskenazi, B., \& Harley, K. G. (2013). Maternal urinary bisphenol a during pregnancy and maternal and neonatal thyroid function in the CHAMACOS study. Environmental Health Perspectives, 121(1), 138-144. https://doi.org/10.1289/ehp.1205092

Chou, W. C., Chen, J. L., Lin, C. F., Chen, Y. C., Shih, F. C., \& Chuang, C. Y. (2011). Biomonitoring of bisphenol A concentrations in maternal and umbilical cord blood in regard to birth outcomes and adipokine expression: a birth cohort study in Taiwan. Environmental Health, 10, 94. https://doi.org/10.1186/1476-069X-10-94

Collet, S. H., Picard-Hagen, N., Viguie, C., Lacroix, M. Z., Toutain, P. L., \& Gayrard, V. (2010). Estrogenicity of bisphenol a: a concentrationeffect relationship on luteinizing hormone secretion in a sensitive model of prepubertal lamb. Toxicological Sciences, 117(1), 54-62. https://doi.org/10.1093/toxsci/kfq186

Corbel, T., Gayrard, V., Viguie, C., Puel, S., Lacroix, M. Z., Toutain, P. L., \& Picard-Hagen, N. (2013). Bisphenol A disposition in the sheep maternal-placental-fetal unit: mechanisms determining fetal internal exposure. Biology of Reproduction, 89(1), 11. https://doi.org/10.1095/ biolreprod.112.106369

Coughtrie, M. W., Burchell, B., Leakey, J. E., \& Hume, R. (1988). The inadequacy of perinatal glucuronidation: immunoblot analysis of the developmental expression of individual UDP-glucuronosyltransferase isoenzymes in rat and human liver microsomes. Molecular Pharmacology, 34(6), 729-735. 
DeBenedictis, B., Guan, H., \& Yang, K. (2016). Prenatal exposure to bisphenol A disrupts mouse fetal liver maturation in a sex-specific manner. Journal of Cellular Biochemistry, 117(2), 344-350. https://doi.org/ $10.1002 / j c b .25276$

Erler, C., \& Novak, J. (2010). Bisphenol a exposure: human risk and health policy. Journal of Pediatric Nursing, 25(5), 400-407. https://doi.org/ 10.1016/j.pedn.2009.05.006

Fowden, A. L., Giussani, D. A., \& Forhead, A. J. (2006). Intrauterine programming of physiological systems: causes and consequences. Physiology (Bethesda), 21, 29-37. https://doi.org/10.1152/ physiol.00050.2005

Gauderat, G., Picard-Hagen, N., Toutain, P. L., Servien, R., Viguie, C., Puel, S., \& Gayrard, V. (2017). Prediction of human prenatal exposure to bisphenol $A$ and bisphenol A glucuronide from an ovine semiphysiological toxicokinetic model. Scientific Reports, 7(1), 1-13. 15330. https://doi.org/10.1038/s41598-017-15646-5

Gerona, R. R., Woodruff, T. J., Dickenson, C. A., Pan, J., Schwartz, J. M., Sen, S., \& Hunt, P. A. (2013). Bisphenol-A (BPA), BPA glucuronide, and BPA sulfate in midgestation umbilical cord serum in a northern and central California population. Environmental Science \& Technology, 47(21), 12477-12485. https://doi.org/10.1021/es402764d

Gingrich, J., Pu, Y., Ehrhardt, R., Karthikraj, R., Kannan, K., \& Veiga-Lopez, A. (2019). Toxicokinetics of bisphenol A, bisphenol S, and bisphenol $F$ in a pregnancy sheep model. Chemosphere, 220, 185-194. https:// doi.org/10.1016/j.chemosphere.2018.12.109

Guignard, D., Gayrard, V., Lacroix, M. Z., Puel, S., Picard-Hagen, N., \& Viguie, C. (2017). Evidence for bisphenol A-induced disruption of maternal thyroid homeostasis in the pregnant ewe at low level representative of human exposure. Chemosphere, 182, 458-467. https:// doi.org/10.1016/j.chemosphere.2017.05.028

Hakim, C., Padmanabhan, V., \& Vyas, A. K. (2017). Gestational hyperandrogenism in developmental programming. Endocrinology, 158(2), 199-212. https://doi.org/10.1210/en.2016-1801

Harley, K. G., Aguilar Schall, R., Chevrier, J., Tyler, K., Aguirre, H., Bradman, A., \& Eskenazi, B. (2013). Prenatal and postnatal bisphenol A exposure and body mass index in childhood in the CHAMACOS cohort. Environmental Health Perspectives, 121(4), 514-520. https://doi.org/10.1289/ ehp.1205548

Ikezuki, Y., Tsutsumi, O., Takai, Y., Kamei, Y., \& Taketani, Y. (2002). Determination of bisphenol A concentrations in human biological fluids reveals significant early prenatal exposure. Human Reproduction, 17(11), 2839-2841. https://doi.org/10.1093/humrep/17.11.2839

Jafari, Z., Mehla, J., Afrashteh, N., Kolb, B. E., \& Mohajerani, M. H. (2017). Corticosterone response to gestational stress and postpartum memory function in mice. PLoS ONE, 12(7), e0180306. https://doi.org/ 10.1371/journal.pone.0180306

Kanaka-Gantenbein, C., Mastorakos, G., \& Chrousos, G. P. (2003). Endocrine-related causes and consequences of intrauterine growth retardation. Annals of the New York Academy of Sciences, 997, 150-157. https://doi.org/10.1196/annals.1290.017

Kobayashi, K., Miyagawa, M., Wang, R. S., Suda, M., Sekiguchi, S., \& Honma, T. (2005). Effects of in utero and lactational exposure to bisphenol A on thyroid status in F1 rat offspring. Industrial Health, 43(4), 685-690. https://doi.org/10.2486/indhealth.43.685

Koneva, L. A., Vyas, A. K., McEachin, R. C., Puttabyatappa, M., Wang, H. S., Sartor, M. A., \& Padmanabhan, V. (2017). Developmental programming: Interaction between prenatal BPA and postnatal overfeeding on cardiac tissue gene expression in female sheep. Environmental and Molecular Mutagenesis, 58(1), 4-18. https://doi.org/10.1002/em.22071

Lang, I. A., Galloway, T. S., Scarlett, A., Henley, W. E., Depledge, M., Wallace, R. B., \& Melzer, D. (2008). Association of urinary bisphenol
A concentration with medical disorders and laboratory abnormalities in adults. JAMA, 300(11), 1303-1310. https://doi.org/10.1001/ jama.300.11.1303

Lee, J., Choi, K., Park, J., Moon, H. B., Choi, G., Lee, J. J., \& Kim, S. (2018). Bisphenol A distribution in serum, urine, placenta, breast milk, and umbilical cord serum in a birth panel of mother-neonate pairs. Science of the Total Environment, 626, 1494-1501. https://doi.org/10.1016/j. scitotenv.2017.10.042

Lee, M. R., Park, H., Bae, S., Lim, Y. H., Kim, J. H., Cho, S. H., \& Hong, Y. C. (2014). Urinary bisphenol A concentrations are associated with abnormal liver function in the elderly: a repeated panel study. Journal of Epidemiology and Community Health, 68(4), 312-317. https://doi.org/ 10.1136/jech-2013-202548

Lee, Y. J., Ryu, H. Y., Kim, H. K., Min, C. S., Lee, J. H., Kim, E., \& Yoon, H. S. (2008). Maternal and fetal exposure to bisphenol A in Korea. Reproductive Toxicology, 25(4), 413-419. https://doi.org/10.1016/j. reprotox.2008.05.058

Mammadov, E., Uncu, M., \& Dalkan, C. (2018). High prenatal exposure to bisphenol A reduces anogenital distance in healthy male newborns. Journal of Clinical Research in Pediatric Endocrinology, 10(1), 25-29. https://doi.org/10.4274/jcrpe.4817

Manikkam, M., Crespi, E. J., Doop, D. D., Herkimer, C., Lee, J. S., Yu, S., \& Padmanabhan, V. (2004). Fetal programming: prenatal testosterone excess leads to fetal growth retardation and postnatal catch-up growth in sheep. Endocrinology, 145(2), 790-798. https://doi.org/10.1210/ en.2003-0478

Meeker, J. D., \& Ferguson, K. K. (2011). Relationship between urinary phthalate and bisphenol A concentrations and serum thyroid measures in U.S. adults and adolescents from the National Health and Nutrition Examination Survey (NHANES) 2007-2008. Environmental Health Perspectives, 119(10), 1396-1402. https://doi.org/10.1289/ehp.1103582

Miao, M., Yuan, W., He, Y., Zhou, Z., Wang, J., Gao, E., \& Li, D. K. (2011). In utero exposure to bisphenol-A and anogenital distance of male offspring. Birth Defects Research. Part a: Clinical and Molecular Teratology, 91(10), 867-872. https://doi.org/10.1002/bdra.22845

Miao, M., Yuan, W., Zhu, G., He, X., \& Li, D. K. (2011). In utero exposure to bisphenol-A and its effect on birth weight of offspring. Reproductive Toxicology, 32(1), 64-68. https://doi.org/10.1016/j. reprotox.2011.03.002

Miller, M. D., Crofton, K. M., Rice, D. C., \& Zoeller, R. T. (2009). Thyroiddisrupting chemicals: interpreting upstream biomarkers of adverse outcomes. Environmental Health Perspectives, 117(7), 1033-1041. https:// doi.org/10.1289/ehp.0800247

MohanKumar, S. M., Rajendran, T. D., Vyas, A. K., Hoang, V., AsirvathamJeyaraj, N., Veiga-Lopez, A., \& MohanKumar, P. S. (2017). Effects of prenatal bisphenol-A exposure and postnatal overfeeding on cardiovascular function in female sheep. Journal of Developmental Origins of Health and Disease, 8(1), 65-74. https://doi.org/10.1017/ S204017441600057X

Moustafa, G. G., \& Ahmed, A. A. M. (2016). Impact of prenatal and postnatal exposure to bisphenol $A$ on female rats in a two generational study: Genotoxic and immunohistochemical implications. Toxicology Reports, 3, 685-695. https://doi.org/10.1016/j.toxrep.2016.08.008

Mullur, R., Liu, Y. Y., \& Brent, G. A. (2014). Thyroid hormone regulation of metabolism. Physiological Reviews, 94(2), 355-382. https://doi.org/ 10.1152/physrev.00030.2013

Nahar, M. S., Kim, J. H., Sartor, M. A., \& Dolinoy, D. C. (2014). Bisphenol Aassociated alterations in the expression and epigenetic regulation of genes encoding xenobiotic metabolizing enzymes in human fetal liver. Environmental and Molecular Mutagenesis, 55(3), 184-195. https://doi. org/10.1002/em.21823 
Nahar, M. S., Liao, C., Kannan, K., Harris, C., \& Dolinoy, D. C. (2015). In utero bisphenol A concentration, metabolism, and global DNA methylation across matched placenta, kidney, and liver in the human fetus. Chemosphere, 124, 54-60. https://doi.org/10.1016/j. chemosphere.2014.10.071

Ong, K. K., Ahmed, M. L., Emmett, P. M., Preece, M. A., \& Dunger, D. B. (2000). Association between postnatal catch-up growth and obesity in childhood: prospective cohort study. BMJ, 320(7240), 967-971. https://doi.org/10.1136/bmj.320.7240.967

Ong, K. K., \& Dunger, D. B. (2002). Perinatal growth failure: the road to obesity, insulin resistance and cardiovascular disease in adults. Best Practice \& Research. Clinical Endocrinology \& Metabolism, 16(2), 191-207. https://doi.org/10.1053/beem.2002.0195

Padmanabhan, V., Sarma, H. N., Savabieasfahani, M., Steckler, T. L., \& Veiga-Lopez, A. (2010). Developmental reprogramming of reproductive and metabolic dysfunction in sheep: native steroids vs. environmental steroid receptor modulators. International Journal of Andrology, 33(2), 394-404. https://doi.org/10.1111/j.1365-2605.2009.01024.x

Padmanabhan, V., Siefert, K., Ransom, S., Johnson, T., Pinkerton, J., Anderson, L., \& Kannan, K. (2008). Maternal bisphenol-A levels at delivery: a looming problem? Journal of Perinatology, 28(4), 258-263. https://doi.org/10.1038/sj.jp.7211913

Padmanabhan, V., \& Veiga-Lopez, A. (2011). Developmental origin of reproductive and metabolic dysfunctions: androgenic versus estrogenic reprogramming. Seminars in Reproductive Medicine, 29(3), 173-186. https://doi.org/10.1055/s-0031-1275519

Peretz, J., Vrooman, L., Ricke, W. A., Hunt, P. A., Ehrlich, S., Hauser, R., \& Flaws, J. A. (2014). Bisphenol A and reproductive health: update of experimental and human evidence, 2007-2013. Environmental Health Perspectives, 122(8), 775-786. https://doi.org/10.1289/ehp.1307728

Philippat, C., Mortamais, M., Chevrier, C., Petit, C., Calafat, A. M., Ye, X., \& Slama, R. (2012). Exposure to phthalates and phenols during pregnancy and offspring size at birth. Environmental Health Perspectives, 120(3), 464-470. https://doi.org/10.1289/ehp.1103634

Romano, M. E., Webster, G. M., Vuong, A. M., Thomas Zoeller, R., Chen, A. Hoofnagle, A. N., \& Braun, J. M. (2015). Gestational urinary bisphenol A and maternal and newborn thyroid hormone concentrations: the HOME Study. Environmental Research, 138, 453-460. https://doi.org/ 10.1016/j.envres.2015.03.003

Romo, A., Carceller, R., \& Tobajas, J. (2009). Intrauterine growth retardation (IUGR): epidemiology and etiology. Pediatric Endocrinology Reviews, 6(Suppl 3), 332-336.

Savabieasfahani, M., Kannan, K., Astapova, O., Evans, N. P., \& Padmanabhan, V. (2006). Developmental programming: differential effects of prenatal exposure to bisphenol-A or methoxychlor on reproductive function. Endocrinology, 147(12), 5956-5966. https://doi.org/ 10.1210/en.2006-0805

Schonfelder, G., Wittfoht, W., Hopp, H., Talsness, C. E., Paul, M., \& Chahoud, I. (2002). Parent bisphenol A accumulation in the human maternal-fetal-placental unit. Environmental Health Perspectives, 110(11), A703-A707. https://doi.org/10.1289/ehp.021100703

Shields, B. M., Knight, B. A., Hill, A., Hattersley, A. T., \& Vaidya, B. (2011). Fetal thyroid hormone level at birth is associated with fetal growth. Journal of Clinical Endocrinology and Metabolism, 96(6), E934-E938. https://doi.org/10.1210/jc.2010-2814

Shimpi, P. C., More, V. R., Paranjpe, M., Donepudi, A. C., Goodrich, J. M., Dolinoy, D. C., \& Slitt, A. L. (2017). Hepatic lipid accumulation and Nrf2 expression following perinatal and peripubertal exposure to bisphenol $\mathrm{A}$ in a mouse model of nonalcoholic liver disease. Environmental Health Perspectives, 125(8), 1-10. 087005. https://doi.org/ 10.1289/EHP664
Smallridge, R. C., \& Ladenson, P. W. (2001). Hypothyroidism in pregnancy: consequences to neonatal health. Journal of Clinical Endocrinology and Metabolism, 86(6), 2349-2353. https://doi.org/10.1210/ jcem.86.6.7577

Snijder, C. A., Heederik, D., Pierik, F. H., Hofman, A., Jaddoe, V. W., Koch, H. M., \& Burdorf, A. (2013). Fetal growth and prenatal exposure to bisphenol A: the generation R study. Environmental Health Perspectives, 121(3), 393-398. https://doi.org/10.1289/ehp.1205296

Sun, Y., Irie, M., Kishikawa, N., Wada, M., Kuroda, N., \& Nakashima, K. (2004). Determination of bisphenol A in human breast milk by HPLC with column-switching and fluorescence detection. Biomedical Chromatography, 18(8), 501-507. https://doi.org/10.1002/bmc.345

Vafeiadi, M., Roumeliotaki, T., Myridakis, A., Chalkiadaki, G., Fthenou, E., Dermitzaki, E., \& Chatzi, L. (2016). Association of early life exposure to bisphenol A with obesity and cardiometabolic traits in childhood. Environmental Research, 146, 379-387. https://doi.org/10.1016/j. envres.2016.01.017

Valsamakis, G., Kanaka-Gantenbein, C., Malamitsi-Puchner, A., \& Mastorakos, G. (2006). Causes of intrauterine growth restriction and the postnatal development of the metabolic syndrome. Annals of the New York Academy of Sciences, 1092, 138-147. https://doi.org/ 10.1196/annals.1365.012

Vandenberg, L. N., Gerona, R. R., Kannan, K., Taylor, J. A., van Breemen, R. B., Dickenson, C. A., \& Woodruff, T. J. (2014). A round robin approach to the analysis of bisphenol A (BPA) in human blood samples. Environmental Health, 13(25), 1-20. https://doi.org/10.1186/1476-069X-13-25

Vandenberg, L. N., Hunt, P. A., Myers, J. P., \& Vom Saal, F. S. (2013). Human exposures to bisphenol A: mismatches between data and assumptions. Reviews on Environmental Health, 28(1), 37-58. https://doi.org/ 10.1515/reveh-2012-0034

Vaughan, O. R., Sferruzzi-Perri, A. N., \& Fowden, A. L. (2012). Maternal corticosterone regulates nutrient allocation to fetal growth in mice. Journal of Physiology, 590(21), 5529-5540. https://doi.org/10.1113/ jphysiol.2012.239426

Veiga-Lopez, A., Beckett, E. M., Abi Salloum, B., Ye, W., \& Padmanabhan, V. (2014). Developmental programming: prenatal BPA treatment disrupts timing of LH surge and ovarian follicular wave dynamics in adult sheep. Toxicology and Applied Pharmacology, 279(2), 119-128. https://doi.org/ 10.1016/j.taap.2014.05.016

Veiga-Lopez, A., Kannan, K., Liao, C., Ye, W., Domino, S. E., \& Padmanabhan, V. (2015). Gender-specific effects on gestational length and birth weight by early pregnancy BPA exposure. Journal of Clinical Endocrinology and Metabolism, 100(11), E1394-E1403. https://doi. org/10.1210/jc.2015-1724

Veiga-Lopez, A., Luense, L. J., Christenson, L. K., \& Padmanabhan, V. (2013). Developmental programming: gestational bisphenol-A treatment alters trajectory of fetal ovarian gene expression. Endocrinology, 154(5), 1873-1884. https://doi.org/10.1210/en.2012-2129

Veiga-Lopez, A., Moeller, J., Sreedharan, R., Singer, K., Lumeng, C., Ye, W., \& Padmanabhan, V. (2016). Developmental programming: interaction between prenatal BPA exposure and postnatal adiposity on metabolic variables in female sheep. American Journal of Physiology. Endocrinology and Metabolism, 310(3), E238-E247. https://doi.org/10.1152/ ajpendo.00425.2015

Veiga-Lopez, A., Pennathur, S., Kannan, K., Patisaul, H. B., Dolinoy, D. C., Zeng, L., \& Padmanabhan, V. (2015). Impact of gestational bisphenol A on oxidative stress and free fatty acids: Human association and interspecies animal testing studies. Endocrinology, 156(3), 911-922. https:// doi.org/10.1210/en.2014-1863

Veiga-Lopez, A., Pu, Y., Gingrich, J., \& Padmanabhan, V. (2018). Obesogenic endocrine disrupting chemicals: identifying knowledge 
gaps. Trends in Endocrinology and Metabolism, 29(9), 607-625. https:// doi.org/10.1016/j.tem.2018.06.003

Veiga-Lopez, A., Steckler, T. L., Abbott, D. H., Welch, K. B., MohanKumar, P. S., Phillips, D. J., \& Padmanabhan, V. (2011). Developmental programming: impact of excess prenatal testosterone on intrauterine fetal endocrine milieu and growth in sheep. Biology of Reproduction, 84(1), 87-96. https://doi.org/10.1095/biolreprod.110.086686

Viguie, C., Collet, S. H., Gayrard, V., Picard-Hagen, N., Puel, S., Roques, B. B., \& Lacroix, M. Z. (2013). Maternal and fetal exposure to bisphenol $a$ is associated with alterations of thyroid function in pregnant ewes and their newborn lambs. Endocrinology, 154(1), 521-528. https://doi. org/10.1210/en.2012-1401

vom Saal, F. S., \& Hughes, C. (2005). An extensive new literature concerning low-dose effects of bisphenol A shows the need for a new risk assessment. Environmental Health Perspectives, 113(8), 926-933. https://doi.org/10.1289/ehp.7713

Vom Saal, F. S., Nagel, S. C., Coe, B. L., Angle, B. M., \& Taylor, J. A. (2012). The estrogenic endocrine disrupting chemical bisphenol A (BPA) and obesity. Molecular and Cellular Endocrinology, 354(1-2), 74-84. https://doi.org/10.1016/j.mce.2012.01.001

Wang, N., Zhou, Y., Fu, C., Wang, H., Huang, P., Wang, B., \& Jiang, Q. (2015). Influence of bisphenol A on thyroid volume and structure independent of iodine in school children. PLoS ONE, 10(10), 1-12. e0141248. https://doi.org/10.1371/journal.pone.0141248

Watson, C. S., Hu, G., \& Paulucci-Holthauzen, A. A. (2014). Rapid actions of xenoestrogens disrupt normal estrogenic signaling. Steroids, 81, 36-42. https://doi.org/10.1016/j.steroids.2013.11.006

Wei, J., Sun, X., Chen, Y., Li, Y., Song, L., Zhou, Z., \& Xu, S. (2014). Perinatal exposure to bisphenol A exacerbates nonalcoholic steatohepatitis-like phenotype in male rat offspring fed on a high-fat diet. Journal of Endocrinology, 222(3), 313-325. https://doi.org/10.1530/JOE-14-0356

Wynne-Edwards, K. E., Edwards, H. E., \& Hancock, T. M. (2013). The human fetus preferentially secretes corticosterone, rather than cortisol, in response to intra-partum stressors. PLoS ONE, 8(6), e63684. https:// doi.org/10.1371/journal.pone.0063684

Xia, W., Jiang, Y., Li, Y., Wan, Y., Liu, J., Ma, Y., \& Xu, S. (2014). Early-life exposure to bisphenol a induces liver injury in rats involvement of mitochondria-mediated apoptosis. PLoS ONE, 9(2), 1-9. e90443. https://doi.org/10.1371/journal.pone.0090443

Xu, X., Liu, Y., Sadamatsu, M., Tsutsumi, S., Akaike, M., Ushijima, H., \& Kato, N. (2007). Perinatal bisphenol A affects the behavior and SRC-1 expression of male pups but does not influence on the thyroid hormone receptors and its responsive gene. Neuroscience Research, 58(2), 149-155. https://doi.org/10.1016/j.neures.2007.02.011

Yang, T. C., Peterson, K. E., Meeker, J. D., Sanchez, B. N., Zhang, Z., Cantoral, A., \& Tellez-Rojo, M. M. (2017). Bisphenol A and phthalates in utero and in childhood: association with child BMI z-score and adiposity. Environmental Research, 156, 326-333. https://doi.org/ 10.1016/j.envres.2017.03.038

Zhang, X., Chang, H., Wiseman, S., He, Y., Higley, E., Jones, P., \& Hecker, M. (2011). Bisphenol A disrupts steroidogenesis in human H295R cells. Toxicological Sciences, 121(2), 320-327. https://doi.org/10.1093/ toxsci/kfrO61

Zoeller, R. T. (2007). Environmental chemicals impacting the thyroid: targets and consequences. Thyroid, 17(9), 811-817. https://doi.org/ $10.1089 /$ thy. 2007.0107

Zoeller, R. T., Bansal, R., \& Parris, C. (2005). Bisphenol-A, an environmental contaminant that acts as a thyroid hormone receptor antagonist in vitro, increases serum thyroxine, and alters RC3/neurogranin expression in the developing rat brain. Endocrinology, 146(2), 607-612. https://doi.org/10.1210/en.2004-1018

\section{SUPPORTING INFORMATION}

Additional supporting information may be found online in the Supporting Information section at the end of the article.

How to cite this article: Vyas AK, Veiga-Lopez A, Ye W, et al. Developmental programming: Sex-specific programming of growth upon prenatal bisphenol A exposure. J Appl Toxicol. 2019;39:1516-1531. https://doi.org/10.1002/jat.3836 